\title{
Clathrin- and dynamin-dependent endocytosis limits canonical NF-KB signaling triggered by lymphotoxin $\beta$ receptor
}

Małgorzata Maksymowicz, Marta Miączyńska and Magdalena Banach-Orłowska* [i]

\begin{abstract}
Background: Lymphotoxin $\beta$ receptor (LT $\beta R$ ) is a member of tumor necrosis factor receptor (TNFR) superfamily which regulates the immune response. At the cellular level, upon ligand binding, the receptor activates the proinflammatory NF-KB and AP-1 pathways. Yet, the intracellular distribution of LT $\beta R$, the routes of its endocytosis and their connection to the signaling activation are not characterized. Here, we investigated the contribution of LT $\beta R$ internalization to its signaling potential.
\end{abstract}

Methods: Intracellular localization of LTRR in unstimulated and stimulated cells was analyzed by confocal microscopy. Endocytosis impairment was achieved through siRNA- or CRISPR/Cas9-mediated depletion, or chemical inhibition of proteins regulating endocytic routes. The activation of LTßR-induced signaling was examined. The levels of effector proteins of the canonical and non-canonical branches of the NF-kB pathway, and the phosphorylation of JNK, Akt, ERK1/2, STAT1 and STAT3 involved in diverse signaling cascades, were measured by Western blotting. A transcriptional response to LT $\beta R$ stimulation was assessed by qRT-PCR analysis.

Results: We demonstrated that LT $\beta R$ was predominantly present on endocytic vesicles and the Golgi apparatus. The ligand-bound pool of the receptor localized to endosomes and was trafficked towards lysosomes for degradation. Depletion of regulators of different endocytic routes (clathrin-mediated, dynamin-dependent or clathrin-independent) resulted in the impairment of LT $\beta R$ internalization, indicating that this receptor uses multiple entry pathways. Cells deprived of clathrin and dynamins exhibited enhanced activation of canonical NF-KB signaling represented by increased degradation of $\mathrm{IkBa}$ inhibitor and elevated expression of $L T \beta R$ target genes. We also demonstrated that clathrin and dynamin deficiency reduced to some extent LTßR-triggered activation of the noncanonical branch of the NF-KB pathway.

Conclusions: Our work shows that the impairment of clathrin- and dynamin-dependent internalization amplifies a cellular response to LTRR stimulation. We postulate that receptor internalization restricts responsiveness of the cell to subthreshold stimuli.

Keywords: Endocytosis, Lymphotoxin $\beta$ receptor, NF-kB signaling, Receptor internalization, Dynamin, Clathrinmediated endocytosis, Clathrin-independent endocytosis

\footnotetext{
* Correspondence: magre@iimcb.gov.pl

Laboratory of Cell Biology, International Institute of Molecular and Cell

Biology, 02-109 Warsaw, Poland
}

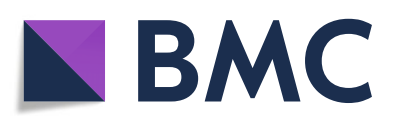

(c) The Author(s). 2020 Open Access This article is licensed under a Creative Commons Attribution 4.0 International License, which permits use, sharing, adaptation, distribution and reproduction in any medium or format, as long as you give appropriate credit to the original author(s) and the source, provide a link to the Creative Commons licence, and indicate if changes were made. The images or other third party material in this article are included in the article's Creative Commons licence, unless indicated otherwise in a credit line to the material. If material is not included in the article's Creative Commons licence and your intended use is not permitted by statutory regulation or exceeds the permitted use, you will need to obtain permission directly from the copyright holder. To view a copy of this licence, visit http://creativecommons.org/licenses/by/4.0/ The Creative Commons Public Domain Dedication waiver (http://creativecommons.org/publicdomain/zero/1.0/) applies to the data made available in this article, unless otherwise stated in a credit line to the data. 


\section{Background}

Lymphotoxin $\beta$ receptor (LT $\beta \mathrm{R})$, a member of tumor necrosis factor receptor superfamily (TNFRSF), is a transmembrane cytokine receptor. It controls the development and maintenance of secondary lymphoid organs: lymph nodes [1] and Peyer's patches [2], and immune cell development [3-6]. LT $\beta R$ is constitutively and ubiquitously expressed, with an exception of $\mathrm{T}$ and $\mathrm{B}$ lymphocytes $[7,8]$, which in turn are the source of its two ligands: lymphotoxin $\alpha 1 \beta 2(\operatorname{LT} \alpha 1 \beta 2)$ and LIGHT $[9,10]$.

Ligand binding by LT $\beta R$ activates signaling cascades, leading to NF- $\mathrm{kB}$ - and AP-1-dependent transcription $[10-15]$. The best characterized in this context is NF- $\kappa B$ signaling, operating via two branches: the canonical and non-canonical ones $[11,12,15]$. Upon stimulation, LT $\beta R$ binds TNFR-associated factor (TRAF) adaptors, that in the canonical branch is followed by proteasomal degradation of a pathway inhibitor, ІкB $\alpha$. This enables RelA/ p50 heterodimer release and translocation to the nucleus. In the non-canonical branch TRAF binding is followed by accumulation of NF- $\mathrm{kB}$-inducing kinase (NIK), leading to the degradation of an inhibitory domain of p100. The resulting transcriptionally active p52 form, together with RelB, acts as a transcription factor (reviewed in [16]). In consequence, activation of both branches induces expression of NF- $\mathrm{kB}$ target genes [11, $12,15,16]$. LT $\beta R$-ligand binding also activates a signaling cascade which operates through AP-1 transcription factors. Within this pathway, the action of mitogenactivated protein kinases (MAPKs), including JNK and ERK1/2, activates c-Jun or ATF2, which together with other proteins (e.g. cFos, JunB) form AP-1 transcription factors $[13,17,18]$. LT $\beta R$ was also reported to regulate the activity of diverse transcription factors, such as STAT1 [19] and STAT3 [20].

Numerous studies show that a particular receptor can be endocytosed via multiple pathways [21-23]. There is a large number of endocytic routes, which are classically divided into clathrin-mediated endocytosis (CME) and clathrinindependent endocytosis (CIE). In CME, cargo is internalized via clathrin-coated pits due to interactions with adaptor proteins. One of them is the adaptor protein 2 (AP2) complex consisting of: $\alpha, \beta 2, \mu 2$ and $\sigma 2$ subunits, among which the $\mu 2$ subunit (encoded by $A P 2 M 1$ gene) is essential for cargo recognition [24, 25]. A nascent clathrincoated vesicle is cut off from the plasma membrane (PM) by a large GTPase, dynamin [26-28]. There are three dynamin proteins in mammalian cells: dynamin-1, expressed mostly in neurons, dynamin-2, which is ubiquitously expressed, and dynamin-3, expressed in neurons, testes and lungs $[29,30]$. It was shown that some cancer cell lines express both dynamin-1 and dynamin-2, which play complementary roles in the regulation of endocytosis [27, 31-33]. Dynamins can also be involved in some forms of CIE [34].
CIE is a general term for various endocytic routes, distinguished based on several criteria: the dependence on dynamin, the type of coating proteins (e.g. caveolins, flotillins) or involvement of small GTPases (e.g. Arf6, Cdc42, RhoA). One example of CIE is a caveolae-dependent pathway. It is regulated by dynamin and operates through caveolae, which are formed by caveolins and cavins [35]. We recently found that LT $\beta R$ internalization depends on cavin-1 [36]. Another CIE route relying on the dynamin activity is RhoA-dependent endocytosis, which is regulated by RhoA together with its effectors, Rho-associated kinases: ROCK1 and ROCK2 [37-39]. In turn, endocytosis involving clathrin-independent carriers (CLIC)/glycosylphosphotidylinositol-anchored protein (GPI-AP) enriched compartments (GEEC), regulated by small GTPase Cdc42, and GTPase activating protein GRAF1, does not require dynamin [40-42]. Moreover, there are routes which involve flotillins [43, 44], Arf6 [34, 45, 46] and curvaturegenerating/sensing membrane protein endophilin. The latter operates both in CME and in one of CIE routes termed fast endophilin mediated endocytosis (FEME) [47].

Endocytosis regulates receptor signaling in different ways. Firstly, internalization decreases the amounts of receptors available on the PM for binding extracellular ligands. Secondly, internalized receptors can be transported via endocytic routes towards degradation or recycled back to the PM that modulates the kinetics and strength of signal transmission [27, 48-51]. Finally, some receptors propagate signals from endosomes, which play a role of intracellular signaling platforms $[52,53]$. While there are many reports on tyrosine kinase receptors (RTKs) and G protein-coupled receptors (GPCRs), showing the link between endocytosis and signaling [23, $54,55]$, the knowledge on such regulation for cytokine receptors is limited [22]. Most of the studies on LT $\beta R$ focus on its role in development and maintenance of immune system [56, 57], as well as its contribution to the progress of different diseases $[10,58]$. In contrast, there are only a few reports on the cell biology of LT $\beta R$.

In our previous research we showed that blocking intracellular trafficking led to the accumulation of ligand-free LT $\beta R$ on endosomes. Depending on the topology of the receptor in endocytic vesicles, it strongly activated NF- $\kappa B$ signaling in a ligand-independent manner (when the receptor was localized on the outer endosomal membrane) [59] or had no effect on signaling (when the receptor was inside intraluminal vesicles of endosomes) [60]. Another study revealed that LT $\beta R$-driven activation of the non-canonical NF-KB pathway required dynamin-2-dependent endocytosis [61].

Internalization, trafficking, intracellular distribution of LT $\beta R$, as well as the link between endocytosis and signaling of LT $\beta R$ are still poorly described. In this study we addressed all these issues. We characterized the 
cellular distribution of the receptor, identified its multiple internalization routes and found clathrin- and dynamin-dependent endocytosis important for the activation of canonical NF-kB signaling.

\section{Methods}

\section{Cell culture and treatments}

A549 pulmonary adenocarcinoma cells (ECACC, \#86012804) were purchased from Sigma-Aldrich. HEK293T, CCD1070Sk and HeLa cell lines were from ATCC. A549 and HEK293T cells were maintained in Dulbecco's Modified Eagle's Medium (DMEM) high glucose, supplemented with $10 \%$ fetal bovine serum (FBS) and $2 \mathrm{mML}$-glutamine (all purchased from SigmaAldrich). HeLa and CCD1070Sk cells were maintained in Modified Eagle's Medium (MEM) high glucose, supplemented with $10 \%$ fetal bovine serum (FBS) and 2 $\mathrm{mM}$ L-glutamine. Mycoplasma contamination tests were routinely performed.

For stimulation and other non-transfection-based experiments, cells were seeded on a 12-well plate (1-2.4x $10^{5}$ cells/well) for Western blotting and quantitative real time PCR (qRT-PCR) experiments, or on $12 \mathrm{~mm}$ coverslips in a 24-well plate $\left(5 \times 10^{4}\right.$ cells/ well) for microscopy, then treated and lysed or fixed the following day. LT $\beta R$ stimulation was performed with anti-LTßR agonistic antibody, Ago (R\&D Systems, \#AF629), Recombinant Human Lymphotoxin

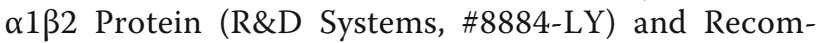
binant Human LIGHT/TNFSF14 Protein (R\&D Systems, \#AF664), all used at concentration $0.2 \mu \mathrm{g} / \mathrm{ml}$. Transferrin-Alexa-Fluor-647 (Thermo Fisher Scientific, \#T23366) was added for $30 \mathrm{~min}$ at concentration $25 \mu \mathrm{g} / \mathrm{ml}$ during stimulation.

The following chemical inhibitors were used to block endocytic routes: dynasore $(100 \mu \mathrm{M}, 1 \mathrm{~h}$ pretreatment; \#HY-15304), chlorpromazine hydrochloride $(20 \mu \mathrm{M}, 0.5$ h pretreatment; \#HY-B0407A) from MedChemExpress, ML141 $(10 \mu \mathrm{M}, 1.5 \mathrm{~h}$ pretreatment; \#SML0407) from Sigma-Aldrich. To inhibit lysosomal degradation, cells were treated with chloroquine (CQ, \#C6628, SigmaAldrich). The concentrations of CQ used in experiments were as follows: $100 \mu \mathrm{M}$ for HeLa, $64 \mu \mathrm{M}$ for A549 and HEK293T and $32 \mu \mathrm{M}$ for CCD1070Sk cells. After $16 \mathrm{~h}$ (HeLa) or $20 \mathrm{~h}$ (A549, HEK293T and CCD1070Sk) of incubation with $\mathrm{CQ}$ or vehicle, cells were additionally stimulated or not for $4 \mathrm{~h}$ with Ago.

All experiments were performed using cells cultured in full medium (DMEM and MEM supplemented with $10 \%$ FBS and $2 \mathrm{mM}$ L-glutamine), except those employing inhibitors of endocytosis and transferrin uptake, where starvation medium (DMEM and MEM supplemented with $2 \mathrm{mM} \mathrm{L}$-glutamine) was applied.

\section{Antibodies and chemicals}

The list of primary antibodies is presented in Additional file 1: Table 1.

Secondary antibodies used for Western blotting, diluted 1:10,000, were as follows: horseradish peroxidase (HRP)-conjugated anti-goat, anti-mouse and anti-rabbit (Jackson ImmunoResearch Labs, \#805-035-180, \#115035-062, \#111-035-144, respectively); secondary fluorophore-conjugated anti-mouse IRDye $800 \mathrm{CW}$ and anti-rabbit IRDye 680CW (LI-COR Biosciences, \#92632,212 and \#926-68,023, respectively).

For immunofluorescence, the following secondary antibodies were used: Alexa Fluor 488-, 555-, 647conjugated anti-goat, anti-mouse and anti-rabbit, purchased from Thermo Fisher Scientific, diluted 1:500. Phalloidin-Atto-390 (\#50556; 1:1000), used for actin staining, was from Sigma-Aldrich.

\section{Transfection with small interfering RNA (siRNAs)}

Reverse transfections with siRNAs were performed with Lipofectamine $^{\circ}$ RNAiMAX transfection reagent (Thermo Fisher Scientific) according to the manufacturer's instructions. A549, HEK293T and CCD1070Sk cells were seeded on a 12-well plate $\left(6-16 \times 10^{4}\right.$ cells/well $)$ for Western blotting and qRT-PCR experiments or on 12 $\mathrm{mm}$ coverslips in a 24-well plate $\left(3 \times 10^{4}\right.$ cells/well $)$ for microscopy (A549 cells only). Cells were analyzed $72 \mathrm{~h}$ post transfection. If cells were stimulated, the ligand was applied for certain time periods prior to lysis or fixation.

We used the following Ambion Silencer Select siRNAs (Thermo Fisher Scientific): Ctrl 1 (Negative Control No. 1, 4,390,843), Ctrl 2 (Negative Control No. 2, 4,390,846), Arf6 1 (s1565; GUCUCAUCUUCGUAGUGGAtt), Arf6 2 (s1566; AGACGGUGACUUACAAAAAtt), Arf6 3 (s1567; CCAAGGUCUCAUCUUCGUAtt), Cdc42 1 (s2765; UGGUGCUGUUGGUAAAACAtt), Cdc42 2 (s2767; CAGUUAUGAUUGGUGGAGAtt), CHC 1 (s475; GGUUGCUCUUGUUACGGAUtt), CHC 2 (s477; GGGAAUUCUUCGUACUCCAtt), Dynamin-1 1 (s144; GCAGUUCGCCGUAGACUUUtt), Dynamin-1 2 (s146; GCACUGCAAGGGAAAGAAAtt), Dynamin-2 1 (s4212; ACAUCAACACGAACCAUGAtt), Dynamin-2 2 (s4214; AGCGAAUCGUCACCACUUAtt), Endophilin-A2 1 (s12796; GCAAGGCGGUGACAGAAGUtt), EndophilinA2 2 (s12797; GACUUUGACUACAAGAAGAtt), Endophilin-A2 3 (s12798; GCUUCAUCGUCUUUCC GAUtt), Flotillin-1 1 (s19913; GCAGAGAAGUCCCA ACUAAtt), Flotillin-1 2 (s19914; GCAUCAGUGU GGUUAGCUAtt), Flotillin-1 3 (s19915; AGAGAG AUUACGAACUGAAtt), Flotillin-2 1 (s5284; CCAAGA UUGCUGACUCUAAtt), Flotillin-2 2 (s5285; ACAGUA AGGUCACAUCAGAtt), Flotillin-2 3 (s5286; GACUAU AAACAGUACGUGUtt), Galectin-3 1 (s8148; GGAGAGUCAUUGUUUGCAAtt), Galectin-3 2 (s8149; 
CGGUGAAGCCCAAUGCAAAtt), Galectin-3 3 (s8150; GACAGUCGGUUUUCCCAUUtt), GRAF1 1 (s23013; GAGCAAGGGCUGUAUCGAAtt), GRAF1 2 (s23015; GGAUACGGAUGAUUGAGAAtt), RhoA 1 (s759; CUAUGAUUAUUAACGAUGUtt), RhoA 2 (s760; GGCUUUACUCCGUAACAGAtt), ROCK1 1 (s12097; GGUUAGAACAAGAGGUAAAtt), ROCK1 2 (s12098; CGGUUAGAACAAGAGGUAAtt), ROCK2 1 (s18162; GAGAUUACCUUACGGAAAAtt), ROCK2 2 (s18161; GGAGAUUACCUUACGGAAAtt).

All siRNAs were used at concentration of $20 \mathrm{nM}$, except double dynamin-1/2 knock-down where each siRNA was used at concentration of $15 \mathrm{nM}$. In case of double dynamin- $1 / 2$ silencing, the following combinations of siRNAs were used: dynamin-1/2 1 (Dynamin- 1 1 \& Dynamin-2 1), dynamin-1/2 2 (Dynamin-1 2 \& Dynamin-2 1), dynamin-1/2 3 (Dynamin-1 1 \& Dynamin-2 2). For these experiments non-targeting siRNAs were combined as follows: Ctrl 1 ( $15 \mathrm{nM}$ of Ctrl 1 and $15 \mathrm{nM}$ of Ctrl 2) and Ctrl 2 (30 $\mathrm{nM}$ of Ctrl 2).

\section{Immunofluorescence and image quantification}

Upon treatment, A549 cells grown on coverslips were transferred to ice and washed with ice-cold PBS, then fixed with $3.6 \%$ paraformaldehyde in PBS for $15 \mathrm{~min}$ at room temperature and kept in $\mathrm{PBS}$ at $4{ }^{\circ} \mathrm{C}$ to be later immunostained, as described previously $[59,62]$.

To stain exclusively the ligand-bound pool of LT $\beta R$, cells stimulated with Ago were incubated without the primary LT $\beta R$ antibody. Instead, only secondary antigoat antibody was used to specifically stain Ago-LTßR complexes [36]. Images were acquired with Zeiss LSM 710 confocal microscope using $40 \times / 1.30$ oil immersion objective and $1024 \times 1024$ pixel resolution, obtaining 10 images per each experimental condition. Images were imported to MotionTracking software (http://motiontracking.mpi-cbg.de) which measures integral intensity (reflecting the amounts of a protein on vesicular structures) and number of vesicles as well as colocalization of stained proteins [63-65]. Figures were assembled in Photoshop (Adobe) with only linear adjustments of contrast and brightness.

\section{Western blot analysis}

Cells were transferred to ice and washed with ice-cold PBS, then lysed in RIPA lysis buffer (1\% Triton X-100, $0.5 \%$ sodium deoxycholate, $0.1 \%$ SDS, $50 \mathrm{mM}$ Tris pH 7.4, $150 \mathrm{mM} \mathrm{NaCl}, 0.5 \mathrm{mM}$ EDTA) in the presence of protease inhibitors $(6 \mu \mathrm{g} / \mathrm{ml}$ chymostatin, $0.5 \mu \mathrm{g} / \mathrm{ml}$ leupeptin, $10 \mu \mathrm{g} / \mathrm{ml}$ antipain, $2 \mu \mathrm{g} / \mathrm{ml}$ aprotinin, $0.7 \mu \mathrm{g} / \mathrm{ml}$ pepstatin A and $10 \mu \mathrm{g} / \mathrm{ml} 4$-amidinophenylmethanesulfonyl fluoride hydrochloride, Sigma-Aldrich) and phosphatase inhibitors (P0044 and P5726, Sigma-Aldrich).
Protein concentration was measured using BCA Protein Assay Kit (Thermo Fisher Scientific). Lysates of 20$30 \mu \mathrm{g}$ protein were boiled in Laemmli sample buffer for $10 \mathrm{~min}$ at $95^{\circ} \mathrm{C}$ and then resolved on $10-12 \%$ polyacrylamide gels, followed by transfer onto nitrocellulose membrane (GE Healthcare). Membranes were first blocked in 5\% milk in PBS-T or 5\% BSA in TBS-T, then incubated overnight with specific primary, and for $1 \mathrm{~h}$ with secondary antibodies. To detect the signal, ChemiDoc system (Bio-Rad) or Odyssey infrared imaging system (LI-COR Biosciences) were used. Densitometry analysis of detected bands was performed with ImageJ Software [66].

\section{Quantitative real-time PCR (qRT-PCR)}

Total RNA was isolated using High Pure RNA Isolation Kit (Roche) in accordance with the manufacturer's protocol. cDNA synthesis was performed using M-MLV reverse transcriptase, random nonamers and oligo $(\mathrm{dT})_{23}$ from Sigma-Aldrich, according to the manufacturer's instructions.

The primers used for qRT-PCR are listed in Additional file 1: Table 2. Reactions were performed with KAPA SYBR FAST qPCR Master Mix (2X) Universal Kit (KK4618, KapaBiosystems), using a 7900HT Fast RealTime PCR System (Applied Biosystems). Data analysis was performed in Data Assist v3.01 software (Applied Biosystems). The expression of target genes was normalized to the level of transcripts of $A C T B$ and $B 2 M$ housekeeping genes, and presented as fold changes.

\section{Generation of AP2M1 knock-out A549 cell lines by CRISPR/Cas9 gene editing}

Knock-out of AP2M1 was performed in A549 cells, using CRISPR/Cas9 gene editing technology as described $[36,60]$. Two 25-bp-long single guide RNA (sgRNAs) were designed using the Brunello library [67] (sequences listed in Additional file 1: Table 3), followed by cloning into LentiCRISPR v2 vector (Addgene \#52961). Additionally, plasmids containing non-targeting sgRNA (kind gift from Dr. Katarzyna Mleczko-Sanecka) were designed as described [68].

Production of lentiviruses, infection of A549 cells, and clonal selection were performed according to the protocol described before [36, 60]. For each sgRNA targeting AP2M1, one clone was selected, based on the best knock-down efficiency. For non-targeting sgRNA four clones were selected and pooled.

\section{Statistical analyses}

Each experiment was done in at least three repetitions. Data were analyzed in Prism 6 (GraphPad Software). To check the significance of differences in fold changes vs control (set as 1), one sample $t$ test was used. The 
significance of mean comparison is annotated as follows: non-significant, ns $-P>0.05,{ }^{*} P \leq 0.05,{ }^{* *} P \leq 0.01$ and **** $P \leq 0.001$.

\section{Results}

LT $\beta R$ localizes to endosomes and Golgi apparatus

In our previous studies we noticed a substantial intracellular pool of LT $\beta R$ which exhibits a complex distribution under basal (unstimulated) conditions in diverse cell lines (HeLa, HEK293 and A549) [36, 59, 60]. More specifically, we observed large perinuclear LT $\beta$ R-positive structures, in addition to vesicular staining. To identify intracellular compartments occupied by LT $\beta R$ in our model A549 cell line, we performed a systematic microscopic analysis of cells stained for LT $\beta R$ and different markers of endosomes (early endosomes: EEA1, late endosomes/lysosomes: LAMP1, Fig. 1a) or the Golgi apparatus (cis-Golgi: GM130, trans-Golgi: TGN46, Fig. 1b). We investigated cells unstimulated $(0 \mathrm{~min})$ and stimulated with agonistic anti-LTßR antibody (Ago) for different time periods (15$240 \mathrm{~min}$ ) to assess if and how the intracellular distribution of LT $\beta R$ is affected by ligand binding. The quantitative analysis of microscopic images confirmed that under unstimulated conditions LT $\beta$ R localized to early and late endosomes [59-61]. We found that the colocalization of LT $\beta R$ with EEA1 peaked at 15-30 min of stimulation with Ago, whereas with LAMP1 at $60 \mathrm{~min}$ (Fig. 1a). Moreover, we noticed that the large perinuclear pool of the receptor colocalizing with Golgi markers was unaffected by administration of Ago (Fig. 1b). Integral intensity of LT $\beta R$ vesicles, a parameter reflecting the amounts of the receptor present specifically in vesicular structures, decreased after $30 \mathrm{~min}$ of incubation with the ligand and subsequently dropped almost by half after $240 \mathrm{~min}$ (Fig. 1a). Western blot analysis of LT $\beta R$ level revealed its progressive decrease starting from $2 \mathrm{~h}$ of stimulation (Fig. 1c). This, together with the colocalization of LT $\beta R$ with the marker of late endosomes/lysosomes, suggested that ligand administration promoted lysosomal degradation of the receptor. Our hypothesis was evaluated in cells pretreated with chloroquine (CQ), a compound inhibiting the activity of lysosomal enzymes by preventing acidification of endosomal compartments. Following the treatment, A549, HEK293T, CCD1070Sk and HeLa cells were unable to reduce the amounts of LT $\beta R$ upon stimulation with Ago as efficiently as control untreated cells (Fig. 1d). It was manifested with higher fold changes of LTRR level in stimulated vs unstimulated cells upon incubation with CQ than under normal conditions (Table in Fig. 1 d).

Our results show that LT $\beta$, regardless of the stimulation status of the cell, is constitutively present on early and late endosomes as well as the Golgi apparatus. However, ligation of the receptor modulates its intracellular distribution and leads to its degradation in lysosomes.

\section{Ligand-bound LT $\beta R$ is trafficked towards lysosomes}

Since LT $\beta R$ is constitutively present on membranes inside the cell, the effect of stimulation on its intracellular distribution and trafficking shown above could be underestimated. Thus, to eliminate this constitutive background we performed microscopic analyses to detect specifically a ligand-bound pool of the receptor. Cells, stimulated as described above, were stained for endocytic markers and the receptor associated with Ago (Fig. 2a), according to our previously optimized protocol [36]. Quantitative analysis of microscopic data revealed significant changes in the integral intensity and the number of LTßR-positive vesicles during stimulation, with the highest values at $30 \mathrm{~min}$ (Fig. $2 \mathrm{~b}$ ). We also confirmed that the localization of Ago-bound LT $\beta R$ on early endosomes was the highest at $30 \mathrm{~min}$ of stimulation, whereas its localization on late endosomes/lysosomes peaked at $60 \mathrm{~min}$ (Fig. 2b). Since we did not observe any staining of intracellular ligand-bound receptor at 240 min (Fig. 2a), we concluded that it was degraded within lysosomes. Thus, the decrease in integral intensity of LT $\beta$ R-positive vesicles showed in Fig. 1a and in receptor protein level in Fig. 1c and d, reflected the degradation of ligand-bound fraction of LT $\beta$.

Taken together, our results show that upon ligand binding LT $\beta R$ is internalized and trafficked via early endosomes to late endosomes/lysosomes for the degradation.

\section{LT $\beta$ R internalization depends on clathrin and dynamin}

We and others previously showed that both ligand-free and ligand-bound LT $\beta R$ undergoes internalization [36, 59-61]. Recently, we demonstrated that depletion of cavin-1 (regulator of caveolae formation) only partially reduced internalization of ligand-bound receptor [36]. Thus, we concluded that another endocytic route/routes should be involved in LT $\beta R$ trafficking. To identify them, we depleted cells of known regulators of different endocytic pathways using RNAi. Then, cells deprived of particular proteins were stimulated with Ago, stained for ligand-bound LT $\beta R$ and EEA1 and analyzed by confocal microscopy. Having characterized the kinetics of LT $\beta R$ trafficking upon ligand stimulation (Fig. 2b), we measured amounts of the internalized ligand-bound receptor (integral intensity) and the number of vesicles occupied by it upon $30 \mathrm{~min}$ of stimulation, when both parameters reached the maximal values (Fig. $2 b$ ).

First, we investigated the contribution of CME to LT $\beta R$ internalization. To this end, we knocked down expression of genes encoding clathrin heavy chain or dynamin-1 and dynamin-2 (Fig. 3a), as both dynamin isoforms were expressed at relatively high levels in A549 cells (Fig. 3b). Depletion of these proteins inhibited internalization of transferrin (Tf), a classical cargo of CME 


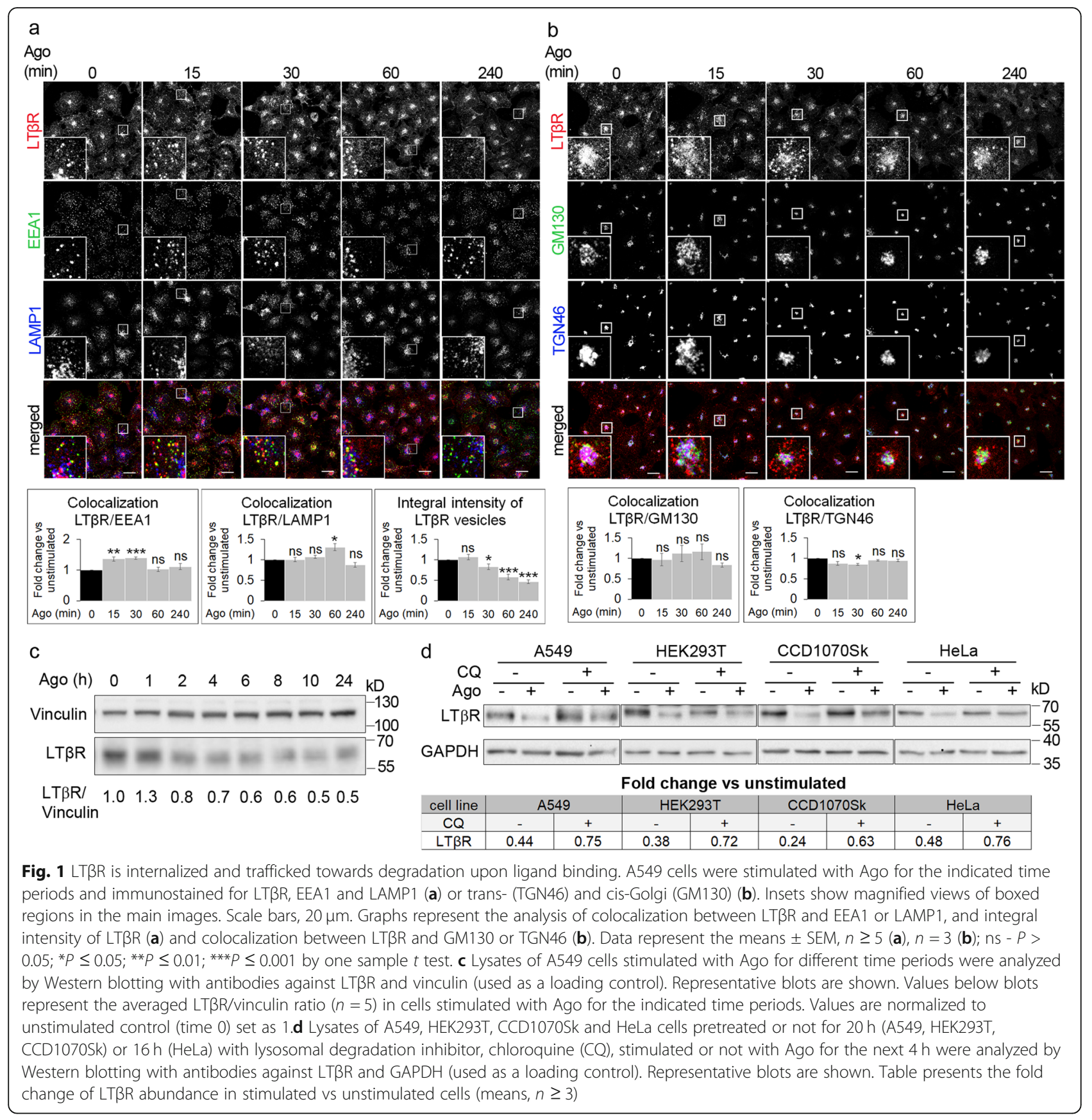

$[69,70]$, as evidenced by $\sim 80 \%$ decrease of integral intensity and the number of Tf-positive vesicles, in comparison to control cells transfected with non-targeting siRNAs (Fig. 3c-f). This testified to efficient blocking of endocytic routes dependent on clathrin and dynamin. Under these conditions, the internalization of LT $\beta R$ was reduced roughly by half, judging by the integral intensities and numbers of LT $\beta$ R-positive vesicles (Fig. 3d, f). However, a degree of reduction varied between cells transfected with different combinations of siRNAs targeting dynamins (Fig. 3f).
To confirm the above results, we blocked CME with alternative methods, using chemical inhibitors: chlorpromazine (CPZ, CME inhibitor [71]) and dynasore (DYN, dynamin inhibitor [72]). We observed a profound inhibition of Tf and LT $\beta R$ internalization in cells treated with these compounds (Additional file 2: Fig. S1a, b).

Yet another way to block CME was to deprive cells of the clathrin adaptor AP2M1 [38]. To this end, we employed a CRISPR/Cas9 genome editing technology, but despite clonal selection, we failed to obtain cells with the complete knock-out (Additional file 2: Fig. S1c). 


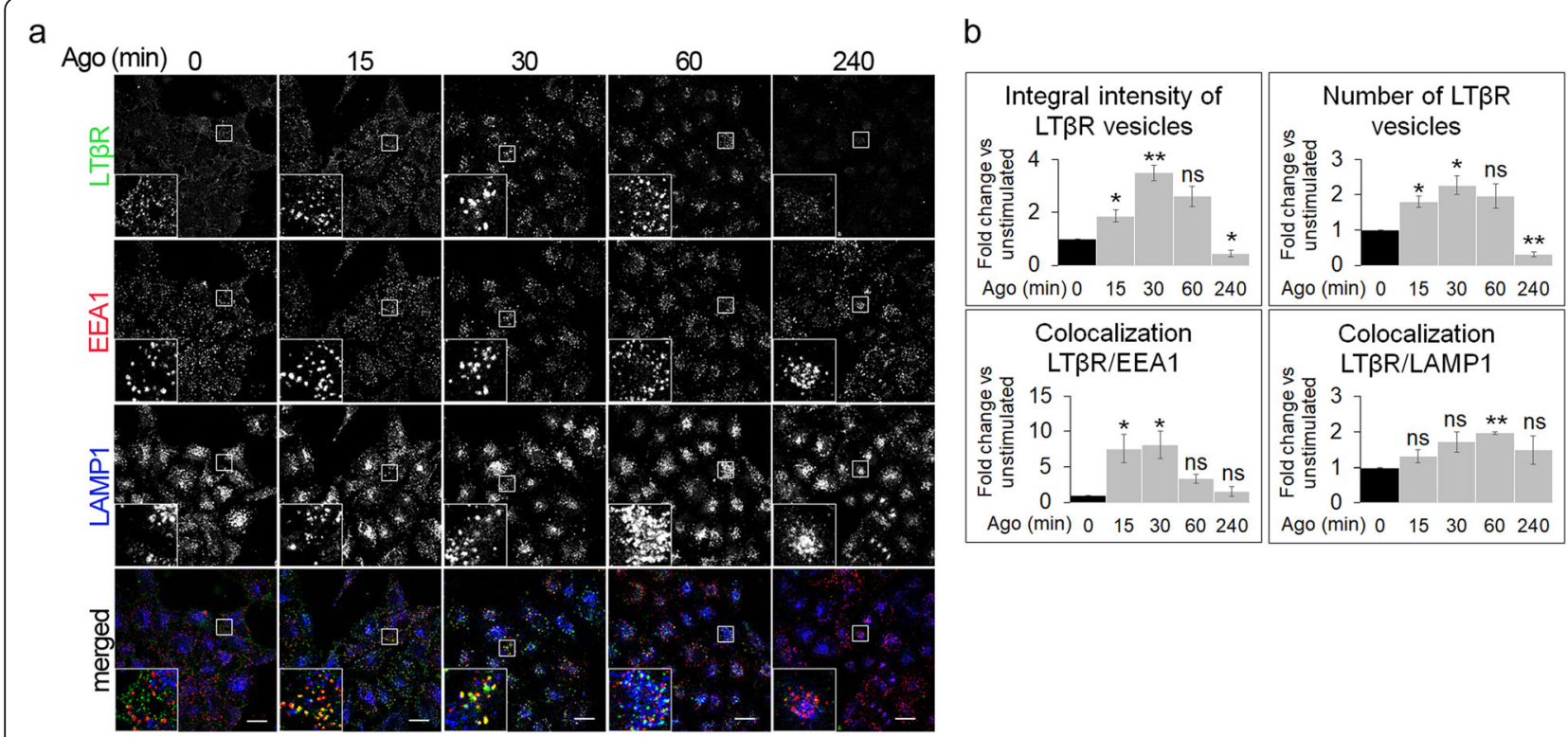

Fig. 2 Ligand-bound LTBR localizes to endocytic compartments. a A549 cells were stimulated with Ago for the indicated time periods and immunostained for ligand-bound LT $\beta R$, EEA1 and LAMP1. Insets show magnified views of boxed regions in the main images. Scale bars, $20 \mu \mathrm{m}$. $\mathbf{b}$ Graphs represent the analysis of integral intensity and number of LTBR vesicles, and colocalization between LTBR and EEA1 or LAMP1. Data represent the means $\pm \mathrm{SEM}, n=4$; ns $-P>0.05 ;{ }^{*} P \leq 0.05 ;{ }^{*} P \leq 0.01$ by one sample $t$ test

Nevertheless, even partial depletion of AP2M1 reduced both, Tf and LT $\beta R$ internalization, roughly by half (Additional file 2: Fig. S1d). This finding clearly indicated that LT $\beta R$ constitutes a cargo recognized by AP2M1, that confirmed a previous observation of Ganeff et al., who found the receptor co-immunoprecipitated with AP2M1 [61]. The interaction between these two proteins probably involves a dileucine motif (localized at the C-terminal part of the receptor [61]), which was postulated to be important for cargo recognition by the AP2 complex [73].

Taken together, our results indicate the involvement of clathrin- and dynamin-dependent routes in LT $\beta R$ internalization. Since efficient blocking of these routes did not completely prevent the internalization of LT $\beta R$, it is plausible that other parallel endocytic pathways are employed by the receptor.

\section{LT $\beta R$ is internalized through CIE pathways}

To identify alternative or additional endocytic route/ routes followed by LT $\beta$ R, we used an analogical strategy to the one described above. We measured internalization of ligand-bound LT $\beta R$ upon impairment of diverse routes of CIE [46], achieved by depletion of their key regulators (Fig. 4a, b). We aimed to impair: CLIC/GEEC (regulated by Cdc42, galectin-3 and GRAF1), RhoAdependent route (regulated by RhoA, ROCK1, ROCK2), Arf6-associated endocytosis, FEME (marked by endophilin-A2), as well as those dependent on the presence of flotillin-1 and flotillin-2. We observed a decrease of the integral intensity and the number of LT $\beta R$ positive vesicles in cells deprived of Cdc42, GRAF1, RhoA, ROCK1, ROCK2 and Arf6, as well as, for single siRNAs, of galectin-3 (Fig. 4c). Endophilin-A2 and flotillin-1 did not seem to be crucial for LT $\beta R$ internalization since their knock-down (Fig. 4a) did not alter either the integral intensity or the number of LT $\beta R$ vesicles (Fig. 4c). In turn, depletion of flotillin-2 increased both analyzed parameters.

To further confirm that LT $\beta R$ is internalized via CLIC/ GEEC, we used Cdc42 inhibitor, ML141, which inhibits GTP binding to this protein [74, 75]. In A549 cells, we examined the status of actin filaments (as their polymerization dynamics depends on Cdc42 [76]), to corroborate the efficacy of Cdc42 inhibition by ML141 (Fig. 4d). Cells treated with the compound exhibited disturbed actin filaments and reduced LT $\beta R$ internalization (Fig. 4d, e). Moreover, the effects of Cdc42 inhibition (Fig. 4e) and depletion (Fig. 4c) on the integral intensity and the number of LT $\beta R$-positive vesicles were comparable.

Cumulatively, our results indicate that LT $\beta R$ internalization occurs through diverse endocytic pathways, which include: CME, Cdc42-regulated CLIC/GEEC, RhoA-dependent and Arf6-associated routes.

\section{The NF-KB pathway is preferentially activated by LT $\beta R$ ligands in $A 549$ cells}

Although LT $\beta$ R was shown to trigger different signaling pathways [10-14], the kinetics of their activation by 


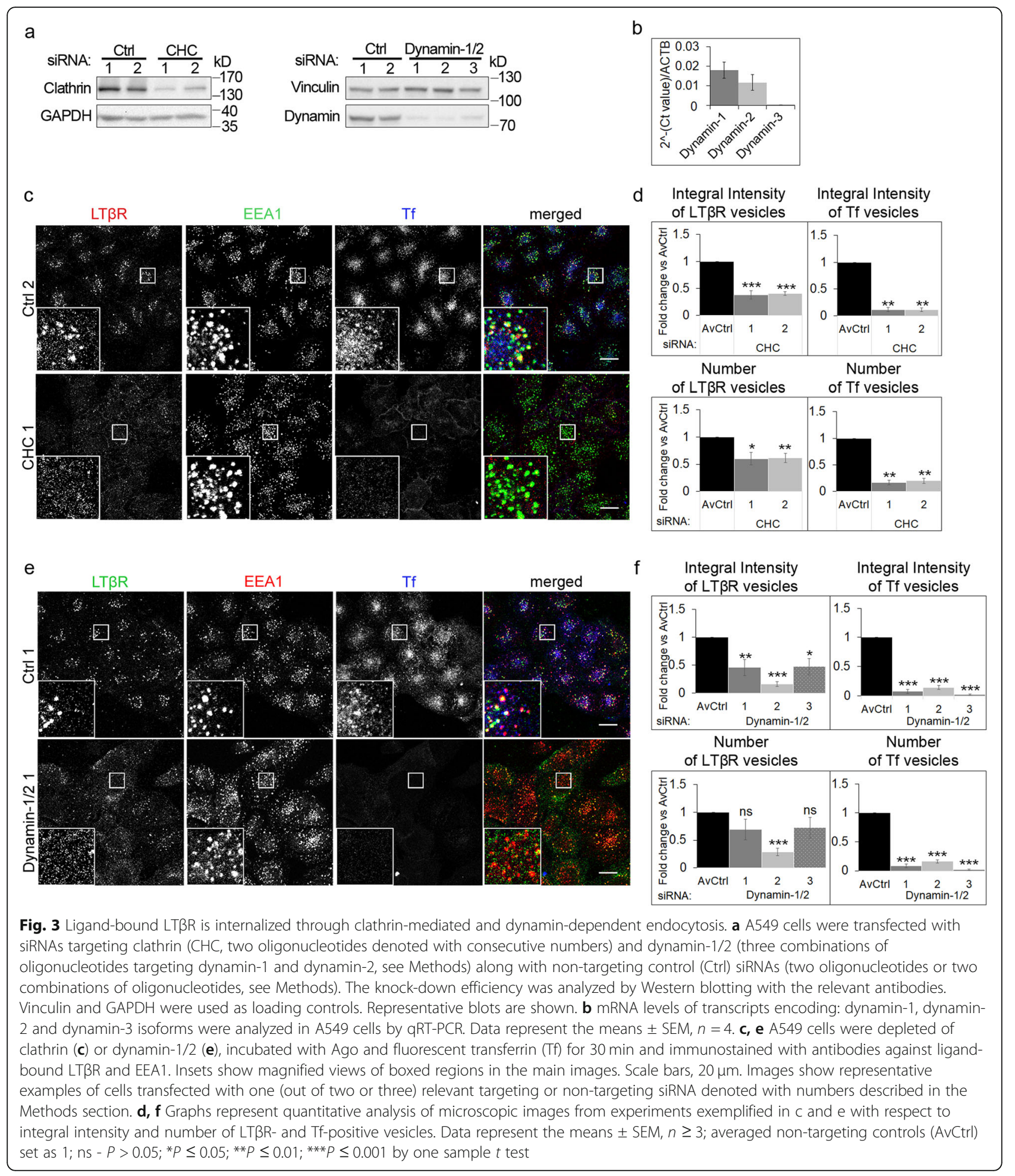

LT $\beta R$ ligands was not studied systematically. To address this issue, we analyzed the status of selected pathways in A549 cells stimulated for various time periods with Ago, LT $\alpha 1 \beta 2$ or LIGHT. We observed that despite minor differences between three ligands, in general they acted in a similar manner (Fig. 5a, b).
With respect to the kinetics of the NF- $\mathrm{kB}$ pathway activation, the degradation of I $\mathrm{B} \alpha \alpha$ inhibitory protein (a hallmark of the canonical branch) was observed at 60 min after ligand administration. In later time points we observed an increase in the level of this protein (Fig. 5a), which confirmed the pathway activation, as ІкB $\alpha$ - 


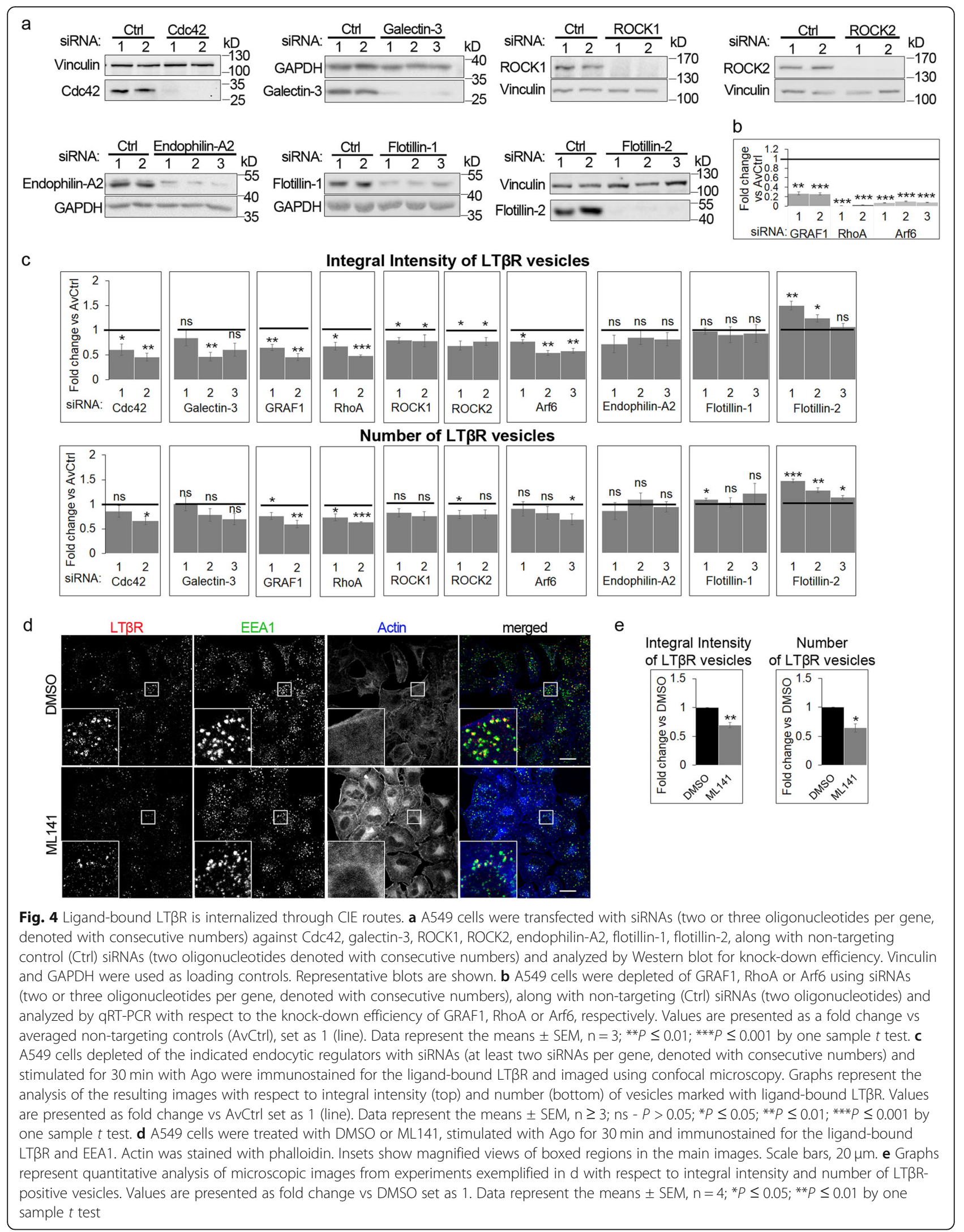




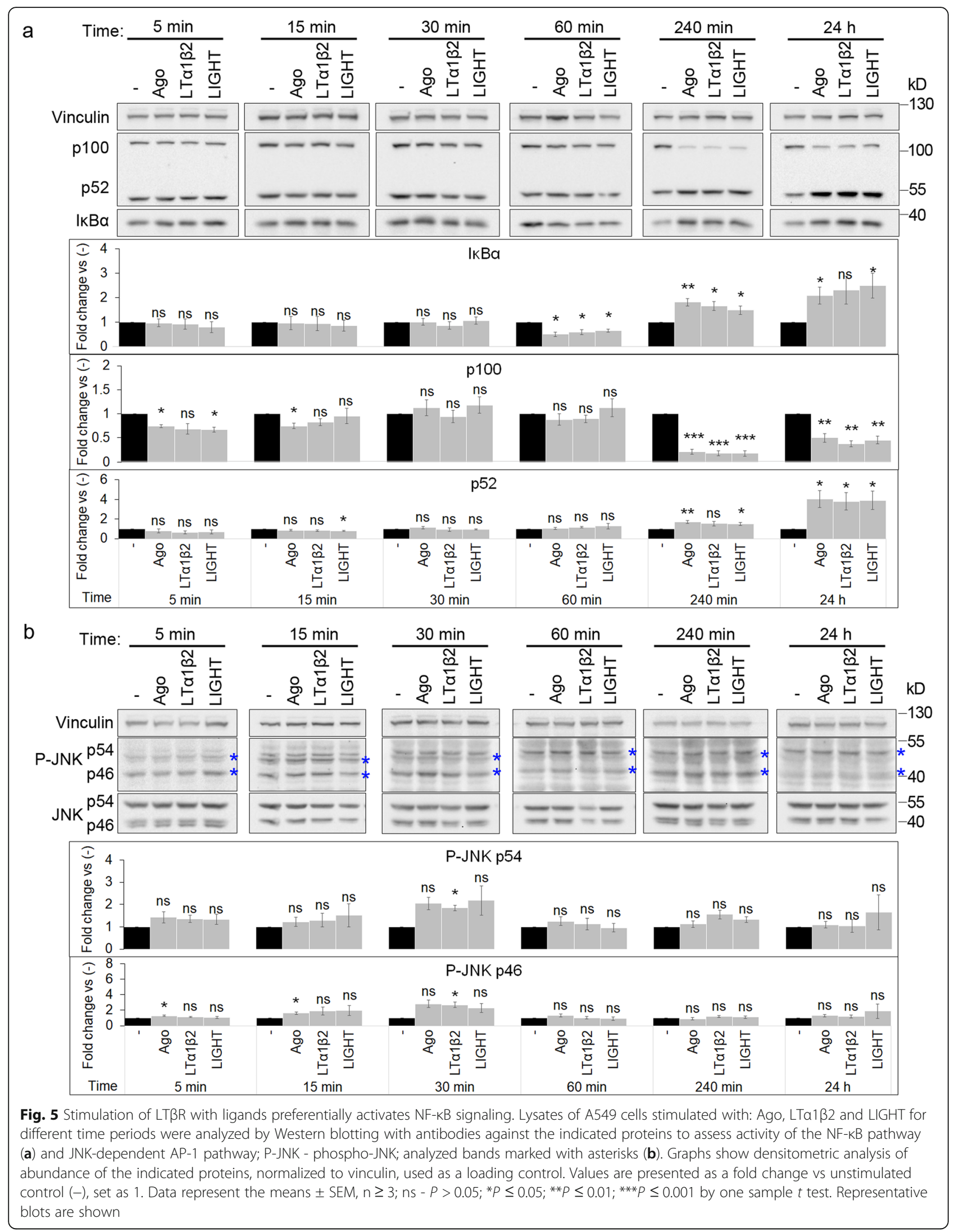


encoding NFKBIA gene is a known NF- $\mathrm{B}$ target [77]. The processing of p100 to transcriptionally potent p52 (a hallmark of the non-canonical NF-кB branch) could be observed at $240 \mathrm{~min}$ of stimulation and continued for the next several hours (Fig. 5a). These data confirmed observations from our previous study [36].

We also investigated the kinetics of activation of JNKdependent AP-1 pathway. We observed only a slight increase of JNK phosphorylation at Thr183/Tyr185 (that reflects its activation) at $30 \mathrm{~min}$ of stimulation with ligands (Fig. 5b).

Finally, we checked the activation of Akt and ERK1/2dependent signaling and the status of STAT1 and STAT3 transcription factors. Akt and ERK1/2 activities, assessed based on the levels of their phosphorylation (Thr202/Tr204 and Ser473, respectively), were not affected under the examined conditions (Additional file 2: Fig. S2a). We also did not observe any significant changes in the activation of STAT1 or STAT3 measured by phosphorylation at Tyr701 and Tyr705, respectively (Additional file 2: Fig. S2b).

Together, our observations indicate that ligand binding by LT $\beta R$ preferentially triggers the NF- $K B$ and, to a small extent, JNK-dependent AP-1 pathways. Thus, we decided to focus on NF- $\mathrm{KB}$ signaling, which seems to be the major pathway activated by LT $\beta R$ in A549 cells.

In parallel to biochemical analyses, we characterized the kinetics of expression of genes encoding cytokines (CCL20, TNF, IL6, CXCL8, CCL5, CCL2), cell adhesion molecules (ICAM1,VCAM1), growth factor (CSF2) and NF-kB pathway regulators (NFKBIA, NFKB2, RELB) that were previously shown to be up-regulated in response to LT $\beta R$ stimulation in A549 cells [36]. We found that the expression of some genes (CCL20, TNF, IL6, CXCL8, $C C L 2$ ) increased early, at $1-4 \mathrm{~h}$ after ligand administration, while others (CCL5, ICAM1, VCAM1, CSF2, $N F K B I A, N F K B 2, R E L B)$ were up-regulated upon longer treatment (Additional file 2: Fig. S3). Moreover, the expression patterns in cells stimulated with different LT $\beta R$ ligands were similar (Additional file 2: Fig. S3), which confirmed the results of biochemical analyses mentioned before (Fig. 5a). Based on the obtained data we selected two time periods of stimulation with Ago ( 2 and $24 \mathrm{~h}$ ) for further studies.

\section{Blocking clathrin- and dynamin-dependent LT $\beta R$ internalization increases activation of the canonical NF-KB pathway}

We previously demonstrated that certain defects in intracellular trafficking of LT $\beta \mathrm{R}$ can lead to strong ligand-independent activation of NF-kB signaling [59]. Furthermore, in our recent study we showed that cholesterol removal from the PM restricted internalization of
LT $\beta R$ and led to strong activation of the canonical branch of the NF- $\mathrm{B}$ pathway in a ligand-dependent manner [36]. To gain better insights into the link between intracellular trafficking and signaling, we investigated if internalization of LT $\beta R$ via the identified endocytic routes influenced its signaling potential. For this purpose, we depleted cells of Cdc42, clathrin, dynamin-1/2, or used relevant inhibitors: ML141, chlorpromazine or dynasore, since under these conditions internalization of ligand-bound LT $\beta$ R was affected the most (Fig. 3, Fig. 4 and Additional file 2: Fig. S1). Following siRNA-mediated knock-down or chemical inhibition of the selected proteins we evaluated the status of the NF- $k B$ pathway.

We found that depletion of Cdc42 did not affect the level of I $\mathrm{KB} \alpha$ (the canonical NF- $\kappa \mathrm{B}$ branch) in unstimulated cells. In turn, degradation of ІкB $\alpha$ in response to LT $\beta R$ stimulation (represented by fold change vs unstimulated conditions, see Table in Additional file 2: Fig. S4a) was either reduced or potentiated, depending on siRNA used for silencing. Thus, to verify Cdc42 effect on activation of LT $\beta R$-triggered canonical NF- $\mathrm{kB}$ signaling, we treated cells with ML141. Administration of the inhibitor had no effect on the levels of IкB $\alpha$ under basal conditions or upon Ago stimulation (Additional file 2: Fig. S4b), denoting that the activation of the canonical NF-kB pathway did not depend on Cdc42. In turn, clathrin depletion potentiated degradation of ІкB $\alpha$ in response to Ago administration in A549 cells (transfected with one of two targeting siRNAs, Fig. 6a). It was confirmed in non-cancer HEK293T and non-transformed fibroblast CCD1070Sk cells (transfected with either of targeting siRNAs, Fig. $6 \mathrm{~b}$ and $\mathrm{c}$ ), despite differences in clathrin depletion efficiency between these cell lines (Fig. $6 \mathrm{~d})$. This, together with the fact that proteolysis of IкB $\alpha$ was enhanced in Ago stimulated cells upon treatment with chlorpromazine (Fig. 6e-g), suggested that CME may regulate the canonical branch of the NF- $k B$ pathway. Similar results were obtained in dynamin-deficient cells, in which stimulation with Ago led to stronger degradation of the pathway inhibitor in comparison to control cells (Fig. 7a-c) in all tested cell lines, regardless of the efficiency of dynamin knock-down (Fig. 3a and Fig. $7 \mathrm{~d}$ ). Also the treatment with dynasore led to stronger degradation of IкB $\alpha$ in A549 and HEK293T cells (Fig. $7 \mathrm{e}, \mathrm{f})$, although it did not seem to affect CCD1070Sk cells (Fig. 7g). The basal levels of ІкB $\alpha$ remained unchanged in cells depleted of dynamin-1/2 (Fig. 7a-c, except one combination of siRNAs in A549 and CCD1070Sk cells) or treated with dynasore (Fig. 7e-g). All these data indicate that canonical NF- $\mathrm{BB}$ signaling driven by LT $\beta R$ activation depends on clathrin- and dynamin-mediated internalization, but not $\mathrm{Cdc} 42-$ regulated endocytosis. 


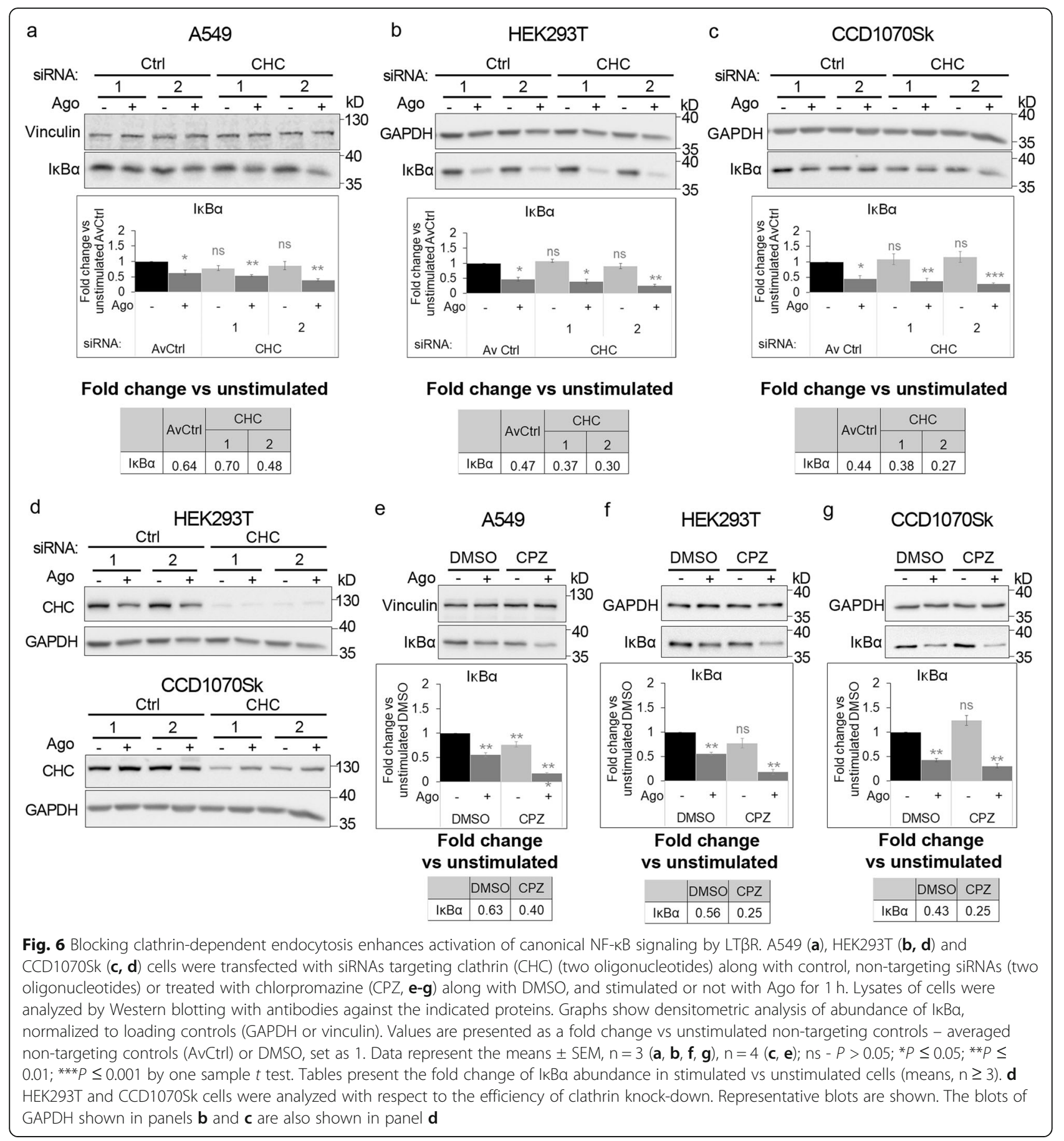

\section{Blocking clathrin- and dynamin-dependent LT $\beta R$ internalization reduces activation of the non-canonical NF-kB pathway}

In parallel, we evaluated how impairment of the abovementioned endocytic routes affected the activation of non-canonical NF- $\mathrm{kB}$ signaling. To this end, we analyzed the status of crucial components of the pathway in cells incubated with Ago for $24 \mathrm{~h}$. We focused on the processing of p100 to p52, presented as the normalized p52/p100 ratio, and the levels of NIK. We noticed that the results from cells depleted of $\mathrm{Cdc} 42$ and those treated with Cdc42 inhibitor (ML141) were not coherent. In Cdc42-depleted cells the p52/p100 ratio was higher than in controls (2.3 and 1.6 vs 1.0 and 1.1), whereas it was lower in ML141-treated cells (0.5 vs 1.0) (Additional file 2: Fig. S5a, b). These data did not allow us to determine a link between Cdc42-regulated endocytosis and non-canonical NF- $\mathrm{kB}$ signaling triggered by 


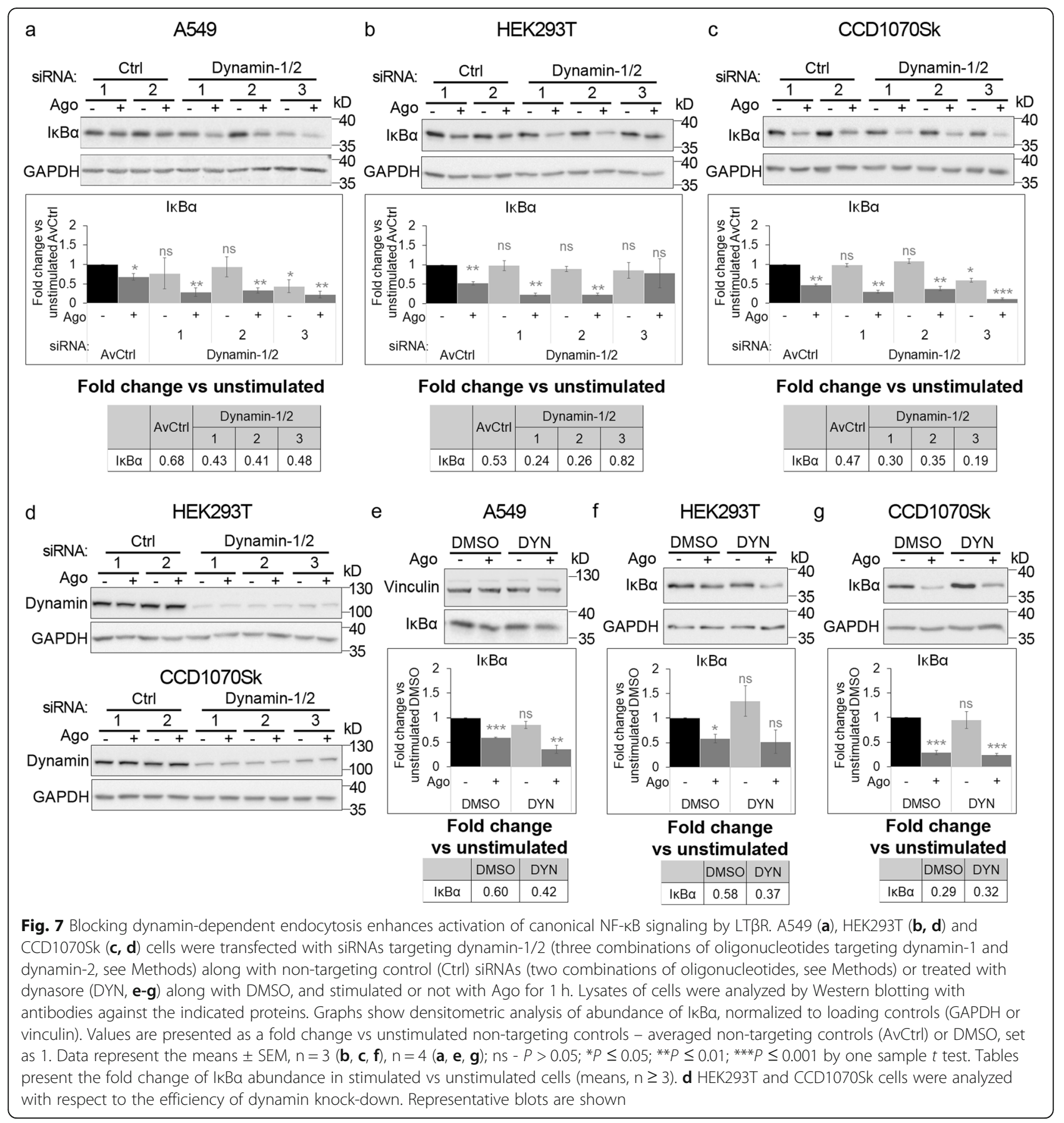

LT $\beta R$. In turn, clathrin depletion reduced p100 processing (lower p52/p100 ratio) in response to LT $\beta R$ stimulation in all tested cell lines (Fig. 8a-c). Similarly, dynamin-1/2 depletion or inhibition with dynasore reduced p100 processing in response to LT $\beta R$ stimulation in A549 cells (Fig. 8d and e). This confirmed previous findings of Ganeff et al. about the role of dynamin in promoting non-canonical NF-kB signaling [61]. Since the reduced p52/p100 ratio in dynamin-depleted A549 cells might partially result from increased level of p100 observed upon dynamin knock-down (Fig. 8d), we assessed the status of an upstream regulator of the noncanonical NF- $\mathrm{KB}$ branch, NIK protein. We found that silencing of dynamin-1/2-encoding genes reduced Agodependent accumulation of NIK (Fig. 8f), which in turn was abolished by dynasore treatment (Fig. 8g).

Our data provided evidence that clathrin-dependent endocytosis is important for non-canonical NF- $\mathrm{kB}$ signaling in diverse cellular models, including carcinoma A549, non-cancer, transformed HEK293T, and non- 


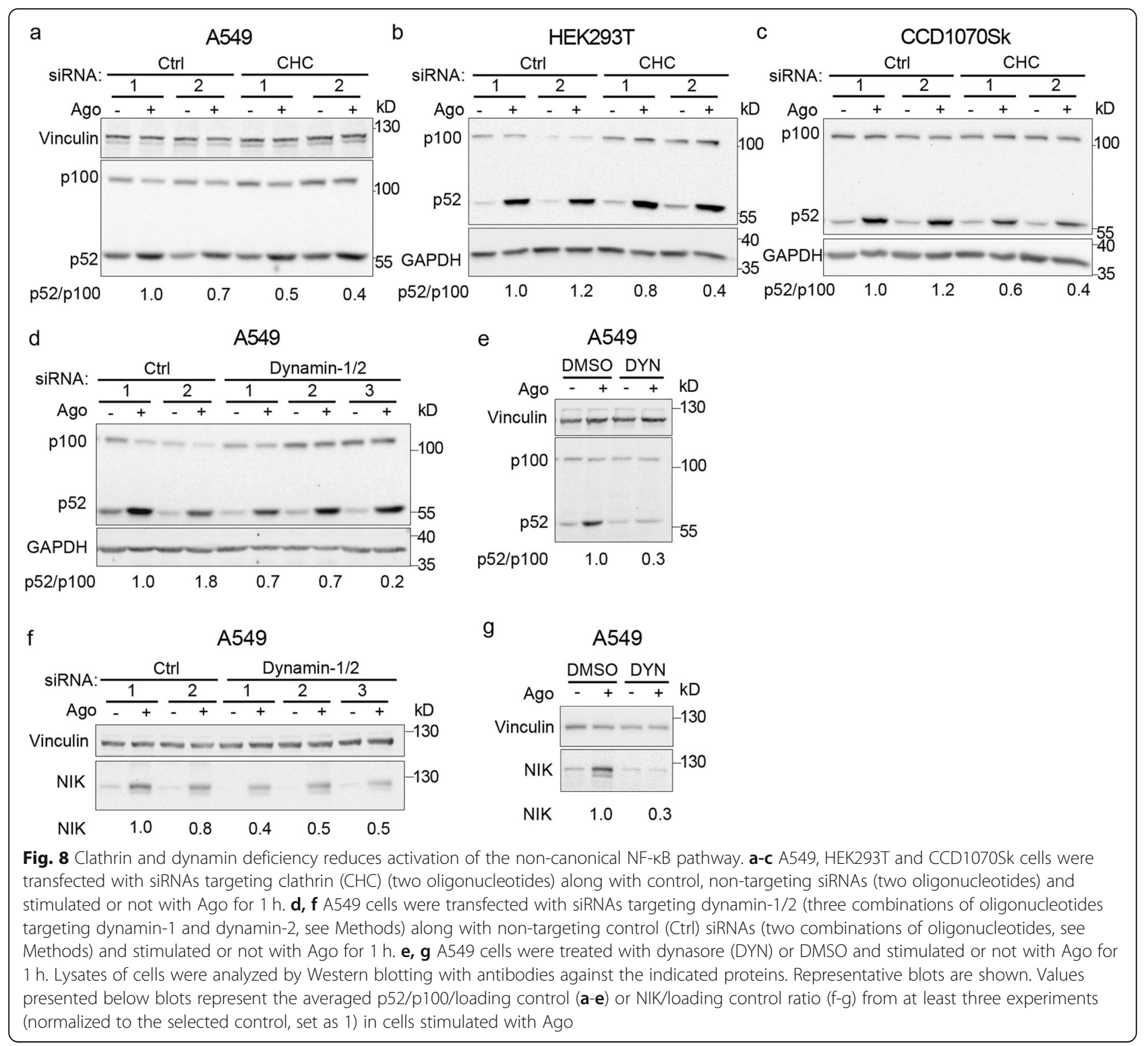

transformed fibroblast CCD1070Sk cells. We also confirmed the previous finding about importance of dynamin-dependent internalization for the noncanonical NF-kB pathway [61].

\section{LT $\beta$ R target gene expression is changed upon clathrin and dynamin depletion}

To further corroborate our observations, we examined if enhanced LT $\beta R$-dependent activation of the canonical NF- $\mathrm{KB}$ pathway upon clathrin and dynamin-1/2 depletion corresponded to changes in the transcription of LT $\beta R$ target genes. We measured the levels of previously selected transcripts in A549 and HEK293T cells depleted of clathrin or dynamin-1/2 and stimulated or not with Ago for $2 \mathrm{~h}$ (Fig. 9 and Additional file 2: Fig. S6). We found that expression of some genes in these cells was changed even under unstimulated conditions in comparison to controls (Fig. 9a, c and Additional file 2: Fig. S6a, c). Moreover, the effect of clathrin and dynamin-1/ 2 knock-down on the transcription of selected genes was cell-type specific, as expected. Thus, to assess the effect of clathrin and dynamin- $1 / 2$ depletion specifically on the responsiveness of cells to LT $\beta R$ stimulation, we calculated the fold change of expression in stimulated vs unstimulated conditions in controls and cells deprived of clathrin or dynamin-1/2 (Fig. 9b, d and Additional file 2: Fig. S6b, d). In agreement with our data presented in Additional file 2: Fig. S3, 2 h stimulation of control A549 cells (transfected with non-targeting siRNAs) with Ago led to a significant increase in the expression of early genes (e.g. CCL20, TNF, IL6, CXCL8, CCL2). This increase varied from 1.7 for CCL2 up to 3.1 fold for 


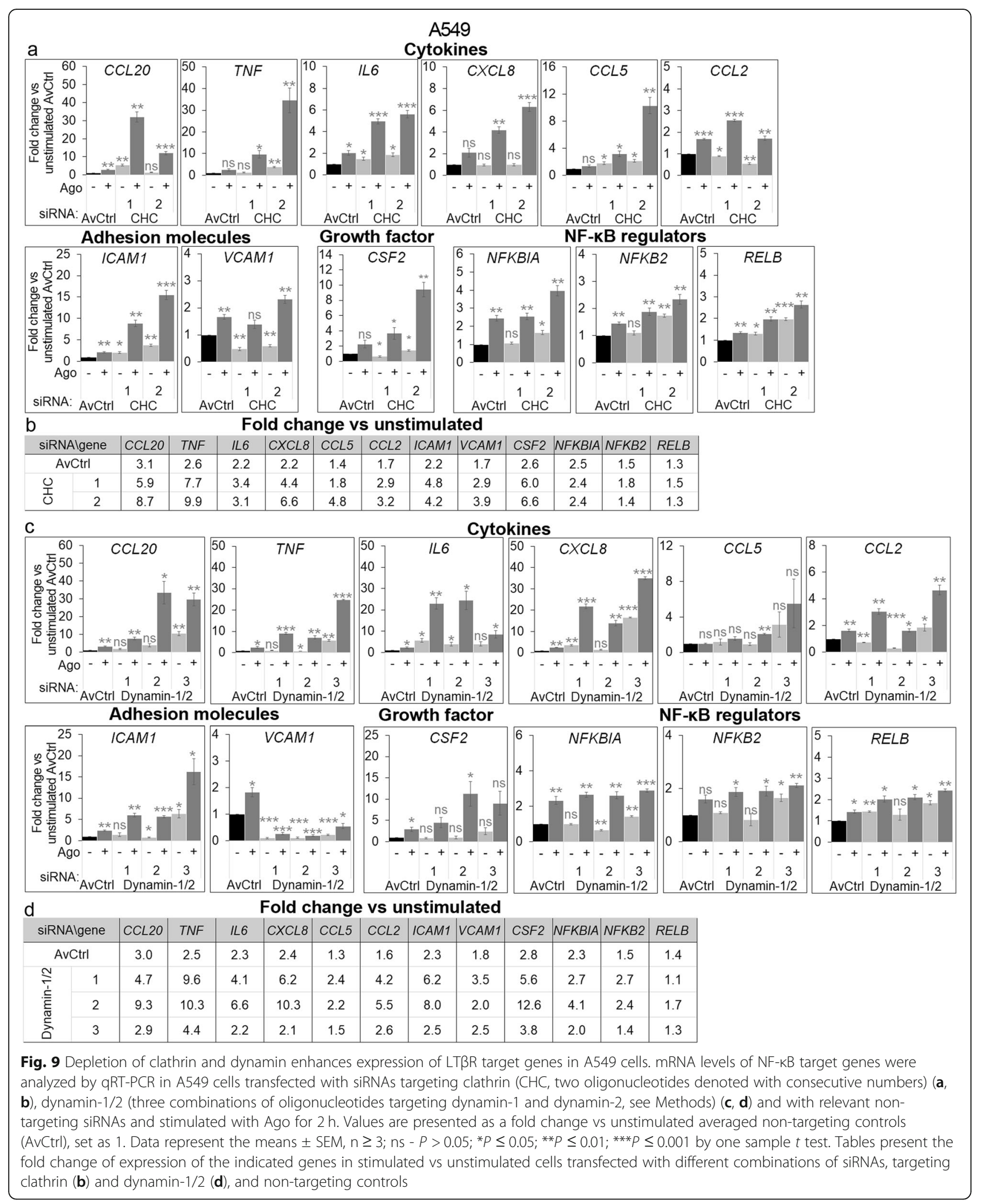

CCL20 in control A549 cells (designated as AvCtrl) from experiments with clathrin depletion (Fig. 9b). Similar increase was observed upon dynamin-1/2 knock-down (1.6 for CCL2, and 3.0 for CCL20, Fig. 9d), although here we applied a combination of non-targeting siRNAs. The results obtained for HEK293T cells confirmed data from 
A549 cell line with minor differences regarding the set of genes affected (Additional file 2: Fig. S6b, d). Comparison of expression fold changes (stimulated vs unstimulated) between control and clathrin- or dynamindepleted cells revealed that following the knock-down, cells were more responsive to the receptor stimulation. Although there were differences between clathrin- and dynamin-deficient cells, and between cells transfected with different siRNAs, the data clearly showed increase in expression of the majority of the examined genes that was further enhanced upon $2 \mathrm{~h}$ of stimulation. The most pronounced effects of endocytosis impairment in A549 cells were observed for early expressed genes, e.g. TNF and CXCL8. We noticed 2.5 fold increase of TNF transcript levels in response to stimulation in control A549 cells, whereas in dynamin-depleted cells this increase varied from 4.4 up to 10.3 fold depending on siRNA combination (Fig. 9d). Although displaying some cell type-specific changes in comparison to A549, HEK293T cells were also sensitized to stimulation with Ago upon silencing of clathrin- and dynamin-1/2-encoding genes (Additional file 2: Fig. S6b, d).

We also examined the impact of clathrin and dynamin-1/2 deprivation on transcription pattern upon prolonged stimulation with Ago in A549 cells. We found that $24 \mathrm{~h}$ after Ago administration the expression of VCAM1 and CSF2 genes was preferentially upregulated in control cells (AvCtrl, Additional file 2: Fig. S7). In clathrin- and dynamin-1/2-depleted cells expression of only selected genes (e.g. CCL20, CCL5, ICAM1) was enhanced in comparison to controls upon $24 \mathrm{~h}$ stimulation with Ago (Additional file 2: Fig. S7b, d).

Taken together, our results indicate that the expression of LT $\beta R$ target genes depends on its endocytosis. The inhibition of LT $\beta R$ internalization potentiates the responsiveness of cells to stimulation of the receptor with the ligand, that is manifested at the level of effector proteins and gene expression.

\section{Discussion}

\section{LT $\beta R$ follows distinct endocytic routes}

It is commonly accepted that endocytosis can influence cellular localization, protein levels, as well as signaling potential of receptors. While many of them were shown to use multiple internalization routes $[21,38]$, the purpose of such variation is vague. Some receptors use different endocytic routes for activation of specific signaling, e.g. TNFR1-dependent NF- $\mathrm{KB}$ pathway activation was shown to depend on clathrin, but not on caveolae [78]. The latter were shown to regulate the activation of RhoA [79] and the PI3K/Akt pathway [80] triggered by the receptor stimulation. In this study we identified the routes of ligand-bound LT $\beta R$ internalization and the consequences of their blocking for signaling triggered by the receptor. So far only a few studies of others and our own pointed to the role of dynamin- and cavin-1dependent endocytosis for LT $\beta R$ function $[36,61]$. Our data indicate that LT $\beta R$ enters a cell mostly via pathways dependent on the activity of dynamins. However, their depletion did not fully abolish LT $\beta$ R internalization, while it almost completely blocked uptake of canonical cargo, Tf. This fact urged us to search for alternative or additional endocytic pathways employed by the receptor. By performing systematic microscopic analysis of LT $\beta R$ internalization we demonstrated that LT $\beta R$ follows multiple endocytic routes to enter a cell upon ligand binding. They include CME, as well as several pathways of CIE: dynamin-independent CLIC/GEEC (since Cdc42 and GRAF1 depletion partially reduced LT $\beta R$ internalization), and dynamin-dependent routes involving RhoA, ROCK1, ROCK2, and Arf6. In addition, and to our surprise, we found that silencing of flotillin-2 caused increased internalization of ligand-bound LT $\beta R$. Based on a similar observation for ErbB2, it was suggested that flotillins rather stabilize this receptor at the PM [81], instead of promoting its internalization. We cannot exclude that the same mechanism operates in case of LT $\beta R$, however we did not examine this scenario further within this study.

We postulate that cells employ distinct endocytic routes to ensure efficient internalization of LT $\beta$ R. It is likely that keeping the receptor amounts at the PM at relatively low levels minimizes unnecessary stimulation of the receptor at the cell surface by subthreshold stimuli. It was proposed that the impairment of endocytic machinery found in glioma cells might lead to prolonged RTK-dependent signaling [82]. In case of LT $\beta R$, endocytosis via multiple routes could constitute a mechanism of protection against over-activation of LT $\beta R$ evoked pro-inflammatory responses, that can be detrimental if not controlled [83]. Moreover, we showed that upon binding of the ligands LT $\beta R$ is sent towards degradation in lysosomes, which reduces its cellular levels. Previously, it was demonstrated that both local accumulation on the limiting membrane of endosomes [59] and overexpression [84] of LT $\beta R$ activate pro-inflammatory signaling even in the absence of a ligand, suggesting that a precise mechanism controlling endocytosis of LT $\beta R$ is crucial.

\section{Signaling triggered by LT $\beta R$ depends on its internalization}

In our recently published study we showed that the reduction of LT $\beta R$ internalization, by acute depletion of the PM cholesterol, enhances LT $\beta R$-triggered proinflammatory canonical NF- $\mathrm{KB}$ signaling [36]. Here we show that ligand-dependent activation of the canonical NF- $\mathrm{KB}$ branch is enhanced upon impairment of dynamin-dependent endocytosis (in cells depleted of dynamin-1 and dynamin-2, or treated with dynasore) 
and upon blocking of CME (by clathrin depletion or treatment with chlorpromazine). This new finding supported our previous observation that there is a correlation between receptor uptake and its signaling potential [36]. However, it is in contrast to the conclusion made by Ganeff et al., who claimed that only the noncanonical branch of NF- $\mathrm{KB}$ signaling depended on dynamin-regulated endocytosis [61]. They did not observe hyper-activation of the canonical NF- $\mathrm{kB}$ pathway (judged by enhanced degradation of IкB $\alpha$ inhibitor) in their model HeLa cells, either upon dynamin depletion/ inhibition, or upon clathrin deprivation. Discrepancy between the present study and the one published by Ganeff et al. could be explained by the use of different cellular models and time periods of receptor stimulation selected for analyses.

Enhanced expression of target genes supported our conclusion about the stronger activation of the canonical NF- $\mathrm{KB}$ route in dynamin- and clathrin-deprived cells. It seems that increase in the levels of most examined transcripts in response to LT $\beta R$ stimulation (fold change stimulated vs unstimulated cells) was higher in cells with impaired endocytosis in comparison to control cells (Fig. 9 \& Additional file 2: Fig. S6 and S7). We observed that the calculated fold changes correlated to some extent with the degree of the reduction of LT $\beta R$ internalization. A549 cells transfected with the combination of dynamin-targeting siRNAs which limited LT $\beta R$ uptake the most effectively (dynamin-1/2 2; Fig. 3f) exhibited the highest responsiveness to the receptor stimulation (Fig. 9). The effect of clathrin- and dynamin-mediated endocytosis impairment on ligand-dependent gene expression was observed mostly for those transcripts, which under conditions of normal endocytosis increased within first $4 \mathrm{~h}$ of the stimulation (Additional file 2: Fig. S3 \& Fig. 9). It may suggest that transcriptional response reflects the activation of immediately triggered signaling pathways, operating via NF- $\mathrm{kB}$ or AP-1 transcription factors. Moreover, our data show enhanced expression of selected targets upon silencing of clathrin or dynamins under ligand-free conditions. This confirms previously reported findings concerning the stimulatory effect of clathrin depletion or dominant negative dynamin-2 mutant on gene transcription $[85,86]$. The sensitivity of clathrin- and dynamin-depleted A549 cells to LT $\beta$ R ligand manifests itself more at the transcriptional level (Fig. 9 \& Additional file 2: Fig. S7) than at the stage of NF- $\mathrm{KB}$ pathway activation (measured by degradation of pathway inhibitor IkB $\alpha$, Fig. 6a \& Fig. 7a). As we showed that both NF-kB and JNK-dependent AP-1 pathways [87] are triggered in A549 cells upon ligand stimulation (Fig. 5), it is possible that the observed difference is a result of an additive effect of activation of distinct signaling pathways.
With respect to the activation of the non-canonical branch of the NF-kB pathway, A549 cells partially recapitulated the results obtained in HeLa cell line by Ganeff et al. [61]. A549 cells deprived of dynamins or treated with dynasore were unable to process p100 to p52 and accumulate NIK as efficiently as it was observed in controls in response to ligand administration (Fig. 8d-g). A more pronounced effect on NIK levels exerted by the treatment with dynasore might be explained by efficient blocking of dynamin activity by dynasore that cannot be achieved by siRNA-mediated knock-down. It is possible that the remaining dynamin molecules in siRNAtransfected cells can still sustain residual activity, that enables some accumulation of NIK. However, it could be insufficient to promote full processing of p100 to p52. This would indicate that under normal conditions dynamin is involved in regulation of the non-canonical NF- $\mathrm{BB}$ pathway at different stages: upstream and downstream from NIK. In contrast to the previously published data [61], our study revealed that clathrin-depleted cells exhibited impaired processing of p100 to p52 in response to stimulation with Ago (Fig. 8a-c). These results indicate that $\mathrm{CME}$ is also important for the activation of the non-canonical NF- $k B$ pathway.

Altogether, our study demonstrates that perturbation in clathrin- and dynamin-dependent endocytosis increases cell responsiveness to LT $\beta R$ stimulation, that leads to the stronger activation of the canonical branch of NF- $\mathrm{KB}$ signaling. We propose that under normal conditions a pro-inflammatory response to LT $\beta R$ ligation is restricted by the receptor internalization via diverse endocytic routes, that prevents prolonged residence of the receptor at the cell surface. Impairment of clathrinand dynamin-dependent endocytosis increases the availability of the receptor for ligand binding at the PM. This in turn enhances LT $\beta R$-triggered canonical NF- $\mathrm{KB}$ and JNK-dependent AP-1 signaling together with transcription of early genes, as it was shown for EGFR-dependent Akt signaling [88]. Alternatively, clathrin and dynamin depletions might activate these pathways in a ligandindependent manner, making cells 'primed' for liganddependent signaling. It was recently shown that macrophages with elevated basal level of NF-кB were more sensitive and faster responding to infection [89]. With respect to the non-canonical NF- $\mathrm{kB}$ pathway, our data support the idea proposed by Ganeff et al. [61]. According to it, dynamin-dependent endocytosis of LT $\beta R$ is crucial for activation of non-canonical branch by the internalized receptor present at the surface of endosomes. We postulate, that under perturbation of endocytosis (either clathrin- or dynamin-dependent) reduced levels of endosomal LT $\beta R$ are insufficient to fully activate noncanonical branch of the NF- $\mathrm{kB}$ pathway. Thus, in cells deprived of clathrin or dynamins, enhancement of 
transcriptional response to prolonged LT $\beta$ R stimulation (observed for selected targets, Additional file 2: Fig. S7) most probably reflects hyper-activation of the canonical branch. Moreover, we cannot exclude that upon impairment of endocytosis LT $\beta R$ affects other signaling pathways (in addition to NF- $\mathrm{kB}$ or $\mathrm{AP}-1$ ), not examined within this study, that in consequence could regulate expression of specific target genes.

Our data hint at existence of a complex endocytosisrelated regulatory machinery of LT $\beta R$-dependent signaling that still is not fully understood. Recognizing the network of pathways affected by LT $\beta R$ endocytosis could broaden our understanding of the receptor biology and direct us towards possible applications of the current data, e.g. in receptor-targeting therapies.

\section{Supplementary information}

Supplementary information accompanies this paper at https://doi.org/10. 1186/s12964-020-00664-0.

Additional file 1 Table 1. List of primary antibodies. Abbreviations: WBWestern blotting, IF-Immunofluorescence. Table 2. List of primers for qRT-PCR. Table 3. List of sgRNA sequences

Additional file 2 Figure $\mathbf{S 1}$ Ligand-bound LT $\beta R$ is internalized through CME. A549 cells treated with DMSO or chlorpromazine (CPZ, a), dynasore (DYN, b) or depleted of AP2M1 through CRISPR/Cas9 genome editing (two non-targeting, NT and two AP2M1 targeting sgRNAs denoted with consecutive numbers) (d) were incubated with Ago and transferrin (Tf) for 30 min and immunostained for the ligand-bound LT $3 R$ and EEA1. Insets show magnified views of boxed regions in the main images. Scale bars, $20 \mu \mathrm{m}$. Graphs represent quantitative analysis of microscopic images from experiments exemplified in $a, b$, and $d$ with respect to integral intensity and number of LT $\beta R$ - and Tf-positive vesicles. Data represent the means \pm SEM, $n=5$ (a), $n=6$ (b), $n=3$ (d). Values are presented as fold change vs DMSO $(a, b)$ or averaged non-targeting controls (AvNT) (d) set as 1 ; ns $-P>0.05$; ${ }^{*} P \leq 0.05$; ${ }^{* *} P \leq 0.01$; ${ }^{* *} P \leq 0.001$ by one sample $t$ test. c Knock-down efficiency of AP2M1 in A549 cells transfected with sgRNAs (two sequences targeting AP2M1 and two non-targeting, NT) and nontransfected, was analyzed by Western blot. Representative blots and images are shown. Figure S2 Stimulation with LTRR ligands does not activate Akt, ERK1/2, STAT1 or STAT3. Lysates of A549 cells stimulated with: Ago, LTa1 $\beta 2$ and LIGHT for different time periods were analyzed by Western blotting with antibodies against the indicated proteins to assess activity of Akt and ERK1/2 (a), and STAT1 and STAT3 (b). P-Akt - phospho-Akt; P-ERK1/2 - phospho-ERK1/2; P-STAT1 - phospho-STAT1; P-STAT3 phospho-STAT3. The blots of vinculin (loading control) in a are also used in lower part of panel b. The blots of vinculin in the upper part of panel $\mathrm{b}$ are also shown in Fig. 5b. Graphs show densitometric analysis of the abundance of the indicated proteins, normalized to loading control. Values are presented as a fold change vs unstimulated control $(-)$, set as 1. Data represent the means $\pm \mathrm{SEM}, n \geq 3$; ns $-P>0.05$; $P \leq 0.05$; ${ }^{* *} P \leq$ 0.01 by one sample $t$ test. Representative blots are shown. Figure S3 Stimulation with LTßR ligands leads to expression of NF-KB target genes. mRNA levels of NF-kB target genes were analyzed by qRT-PCR in A549 cells stimulated with: Ago, LTa1 32 and LIGHT for different time periods. Values are presented as a fold change vs unstimulated cells. Data represent the means \pm SEM, $n=3$. Figure S4 Cdc42 deficiency does not affect the activation of canonical NF-KB signaling by LTRR. A549 cells were: transfected with siRNAs targeting Cdc42 (two oligonucleotides) (a) or treated with ML141 (b), along with the relevant controls, non-targeting siRNAs (two oligonucleotides, Ctrl) (a) or DMSO (b), and stimulated or not with Ago for $1 \mathrm{~h}$. Lysates of cells were analyzed by Western blotting with antibodies against the indicated proteins. Representative blots are shown. Graphs show densitometric analysis of abundance of IkBa, normalized to loading control (GAPDH). Values are presented as a fold change vs unstimulated non-targeting controls - averaged non-targeting controls (AvCtrl) or DMSO, set as 1. Data represent the means $\pm \mathrm{SEM}, n=4$ (a), $\mathrm{n}=3$ (b); $\mathrm{ns}-P>0.05 ;{ }^{*} P \leq 0.05 ;{ }^{*} P \leq 0.01$ by one sample $t$ test. Tables present the fold change of $1 \mathrm{kBa}$ abundance in stimulated $v$ s unstimulated cells (means, $n \geq 3$ ). Figure S5 Cdc42 deficiency does not affect the activation of non-canonical NF-kB signaling by LT $\beta R$. A549 cells were: transfected with siRNAs targeting Cdc42 (two oligonucleotides) (a) or treated with ML141 (b), along with the relevant controls, non-targeting siRNAs (two oligonucleotides, Ctrl) (a) or DMSO (b), and stimulated or not with Ago for $24 \mathrm{~h}$. Lysates of cells were analyzed by Western blotting with antibodies against the indicated proteins. Representative blots are shown. Values presented below blots represent the averaged p52/p100/loading control ratio from at least three experiments (normalized to GAPDH, set as 1) in cells stimulated with Ago. Figure S6 Depletion of clathrin and dynamin enhances expression of LT $\beta$ R target genes in HEK293T cells. mRNA levels of NF-KB target genes were analyzed by qRT-PCR in HEK293T cells transfected with siRNAs targeting clathrin (CHC, two oligonucleotides denoted with consecutive numbers) (a, b), dynamin-1/2 (three combinations of oligonucleotides targeting dynamin-1 and dynamin-2, see Methods) (c, d) and with relevant non-targeting siRNAs and stimulated with Ago for $2 \mathrm{~h}$. Values are presented as a fold change vs unstimulated averaged non-targeting controls (AvCtrl), set as 1. Data represent the means $\pm \mathrm{SEM}, \mathrm{n}=3$; $\mathrm{ns}-P>0.05$; ${ }^{*} P \leq 0.05$; ${ }^{* *} P \leq 0.01$; *** $P \leq 0.001$ by one sample $t$ test. Tables present the fold change of expression of the indicated genes in stimulated vs unstimulated cells transfected with different combinations of siRNAs, targeting clathrin (b) and dynamin-1/2 (d), and non-targeting controls. Figure S7 Depletion of clathrin and dynamin enhances expression of the selected LT $\beta R$ target genes in A549 cell upon prolonged stimulation. mRNA levels of NF-KB target genes were analyzed by qRT-PCR in A549 cells transfected with siRNAs targeting clathrin (CHC) (two oligonucleotides) (a, b) or dynamin$1 / 2$ (three combinations of oligonucleotides targeting dynamin-1 and dynamin-2, see Methods) (c, d) and stimulated with Ago for $24 \mathrm{~h}$. Values are presented as a fold change vs unstimulated averaged non-targeting controls (AvCtrl), set as 1. Data represent the means $\pm S E M, n=3$; ns $P>0.05 ;{ }^{*} P \leq 0.05 ;{ }^{* *} P \leq 0.01 ;{ }^{* * *} P \leq 0.001$ by one sample $t$ test. Tables present the fold change of the indicated gene expression in stimulated vs unstimulated cells transfected with siRNAs, targeting clathrin (b) and dynamin-1/2 (d) and non-targeting controls.

\section{Abbreviations}

Ago: Agonistic anti-LTßR antibody; AP-1: Activator protein 1; AP2: Adaptor protein 2; CIE: Clathrin-independent endocytosis; CHC: Clathrin heavy chain; CLIC/GEEC: Clathrin-Independent carriers/glycosylphosphotidylinositolanchored protein (GPI-AP) enriched compartments endocytosis; CME: Clathrin-mediated endocytosis; CPZ: Chlorpromazine hydrochloride; DYN: Dynasore; CQ: Chloroquine; EEA1: Early endosome antigen 1; ERK1/ 2: Extracellular signal-regulated kinase 1 and extracellular signal-regulated kinase 2; FEME: Fast endophilin mediated endocytosis; GM130: Golgi matrix protein $130 \mathrm{kDa}$; GPCR: G protein-coupled receptor; JNK: c-Jun N-terminal kinase; LAMP1: Lysosomal associated membrane protein 1; LIGHT: Homologous to lymphotoxin, exhibits inducible expression and competes with HSV glycoprotein D for binding to herpesvirus entry mediator, a receptor expressed on T lymphocytes; LTa1 32 : Lymphotoxin a1 $\beta 2 ;$

LTRR: Lymphotoxin $\beta$ receptor; MAPK: Mitogen-activated protein kinase; NFKB: Nuclear factor kappa-light-chain-enhancer of activated B cells; NIK: NF-KBinducing kinase; PM: Plasma membrane; RTK: Receptor tyrosine kinase; STAT: Signal transducer and activator of transcription; Tf: Transferrin; TGN46: Trans-Golgi network protein 2; TNFRSF: Tumor necrosis factor receptor superfamily; TRAF: TNF receptor associated factor

\section{Acknowledgements}

We thank Dr. Daria Zdżalik-Bielecka, Agata Poświata, Marta Kaczmarek and Renata Wyszyńska for critical reading of the manuscript and Renata Wyszyńska for technical support. We acknowledge Dr. Katarzyna MleczkoSanecka for sharing control non-targeting sgRNAs. 


\section{Authors' contributions}

The research was conceived by MBO with support of MMia. Funding was acquired by MBO. Experiments were designed, performed and analyzed by MMaks and MBO with help from MMią. The manuscript was written by MMaks and MBO with input from MMią. Figures were assembled by MMaks and MBO. The authors approved the manuscript.

\section{Funding}

This work was supported by OPUS grant (UMO-2016/21/B/NZ3/03637) to $\mathrm{MBO}$ from National Science Centre.

\section{Availability of data and materials}

The datasets used and/or analyzed during the current study are available on reasonable request.

\section{Ethics approval and consent to participate}

Not applicable.

\section{Consent for publication}

All authors agreed on the manuscript.

\section{Competing interests}

The authors declare that they have no competing interests.

Received: 12 March 2020 Accepted: 18 September 2020

Published online: 04 November 2020

\section{References}

1. Futterer A, Mink K, Luz A, Kosco-Vilbois MH, Pfeffer K. The lymphotoxin beta receptor controls organogenesis and affinity maturation in peripheral lymphoid tissues. Immunity. 1998;9(1):59-70 Epub 1998/08/11.

2. Yilmaz ZB, Weih DS, Sivakumar V, Weih F. RelB is required for Peyer's patch development: differential regulation of p52-RelB by lymphotoxin and TNF. EMBO J. 2003;22(1):121-30 Epub 2002/12/31

3. Fu YX, Huang G, Matsumoto M, Molina H, Chaplin DD. Independent signals regulate development of primary and secondary follicle structure in spleen and mesenteric lymph node. Proc Natl Acad Sci U S A. 1997;94(11):5739-43 Epub 1997/05/27.

4. lizuka K, Chaplin DD, Wang Y, Wu Q, Pegg LE, Yokoyama WM, et al. Requirement for membrane lymphotoxin in natural killer cell development. Proc Natl Acad Sci U S A. 1999;96(11):6336-40 Epub 1999/05/26.

5. Smyth MJ, Johnstone RW, Cretney E, Haynes NM, Sedgwick JD, Korner H, et al. Multiple deficiencies underlie NK cell inactivity in lymphotoxin-alpha gene-targeted mice. J Immunol. 1999;163(3):1350-3 Epub 1999/07/22.

6. Piao W, Xiong Y, Famulski K, Brinkman CC, Li L, Toney N, et al. Regulation of $T$ cell afferent lymphatic migration by targeting LTbetaR-mediated nonclassical NFkappaB signaling. Nat Commun. 2018;9(1):3020 Epub 2018/08/03.

7. Force WR, Walter BN, Hession C, Tizard R, Kozak CA, Browning JL, et al. Mouse lymphotoxin-beta receptor. Molecular genetics, ligand binding, and expression. J Immunol. 1995;155(11):5280-8 Epub 1995/12/01.

8. Murphy M, Walter BN, Pike-Nobile L, Fanger NA, Guyre PM, Browning JL, et al. Expression of the lymphotoxin beta receptor on follicular stromal cells in human lymphoid tissues. Cell Death Differ. 1998;5(6):497-505 Epub 1999/ 04/14.

9. Crowe PD, Vanarsdale TL, Walter BN, Ware CF, Hession C, Ehrenfels B, et al. Pillars article: a lymphotoxin-B-specific receptor. Science. 1994. 264: 707-710. J Immunol. 2014;192(5):2015-8 Epub 2014/02/25

10. Fernandes MT, Dejardin E, dos Santos NR. Context-dependent roles for lymphotoxin-beta receptor signaling in cancer development. Biochim Biophys Acta. 2016;1865(2):204-19 Epub 2016/03/01.

11. Dejardin E, Droin NM, Delhase M, Haas E, Cao Y, Makris C, et al. The lymphotoxin-beta receptor induces different patterns of gene expression via two NF-kappaB pathways. Immunity. 2002;17(4):525-35 Epub 2002/10/22.

12. Muller JR, Siebenlist U. Lymphotoxin beta receptor induces sequential activation of distinct NF-kappa B factors via separate signaling pathways. J Biol Chem. 2003;278(14):12006-12 Epub 2003/01/31.

13. Kim YS, Nedospasov SA, Liu ZG. TRAF2 plays a key, nonredundant role in LIGHT-lymphotoxin beta receptor signaling. Mol Cell Biol. 2005;25(6):2130-7 Epub 2005/03/04.

14. Sudhamsu J, Yin J, Chiang EY, Starovasnik MA, Grogan JL, Hymowitz SG Dimerization of LTbetaR by LTalpha1 beta2 is necessary and sufficient for signal transduction. Proc Natl Acad Sci U S A. 2013;110(49):19896-901 Epub 2013/11/20

15. Chang YH, Hsieh SL, Chen MC, Lin WW. Lymphotoxin beta receptor induces interleukin 8 gene expression via NF-kappaB and AP-1 activation. Exp Cell Res. 2002;278(2):166-74 Epub 2002/08/10.

16. Zhang Q, Lenardo MJ, Baltimore D. 30 years of NF-kappaB: a blossoming of relevance to human pathobiology. Cell. 2017;168(1-2):37-57 Epub 2017/01/ 14.

17. Davis RJ. Signal transduction by the JNK group of MAP kinases. Cell. 2000; 103(2):239-52 Epub 2000/11/01.

18. Johnson GL, Lapadat R. Mitogen-activated protein kinase pathways mediated by ERK, JNK, and p38 protein kinases. Science. 2002;298(5600): 1911-2 Epub 2002/12/10.

19. Kutsch S, Degrandi D, Pfeffer K. Immediate lymphotoxin beta receptormediated transcriptional response in host defense against $\mathrm{L}$. monocytogenes. Immunobiology. 2008;213(3-4):353-66 Epub 2008/04/15.

20. Tumanov AV, Koroleva EP, Christiansen PA, Khan MA, Ruddy MJ, Burnette B, et al. T cell-derived lymphotoxin regulates liver regeneration. Gastroenterology. 2009:136(2):694-704 e4 Epub 2008/10/28.

21. Tomas A, Futter CE, Eden ER. EGF receptor trafficking: consequences for signaling and cancer. Trends Cell Biol. 2014;24(1):26-34 Epub 2013/12/04.

22. Cendrowski J, Maminska A, Miaczynska M. Endocytic regulation of cytokine receptor signaling. Cytokine Growth Factor Rev. 2016;32:63-73 Epub 2016/ $07 / 28$.

23. Goh LK, Sorkin A. Endocytosis of receptor tyrosine kinases. Cold Spring Harb Perspect Biol. 2013;5(5):a017459 Epub 2013/05/03.

24. Boucrot E, Saffarian S, Zhang R, Kirchhausen T. Roles of AP- 2 in clathrinmediated endocytosis. PLoS One. 2010;5(5):e10597 Epub 2010/05/21.

25. Kadlecova Z, Spielman SJ, Loerke D, Mohanakrishnan A, Reed DK, Schmid SL. Regulation of clathrin-mediated endocytosis by hierarchical allosteric activation of AP2. J Cell Biol. 2017;216(1):167-79 Epub 2016/12/23.

26. McMahon HT, Boucrot E. Molecular mechanism and physiological functions of clathrin-mediated endocytosis. Nat Rev Mol Cell Biol. 2011;12(8):517-33 Epub 2011/07/23.

27. Schmid SL. Reciprocal regulation of signaling and endocytosis: implications for the evolving cancer cell. J Cell Biol. 2017;216(9):2623-32 Epub 2017/07/05.

28. Mettlen M, Chen PH, Srinivasan S, Danuser G, Schmid SL. Regulation of Clathrin-mediated endocytosis. Annu Rev Biochem. 2018;87:871-96 Epub 2018/04/18.

29. Cook T, Mesa K, Urrutia R. Three dynamin-encoding genes are differentially expressed in developing rat brain. J Neurochem. 1996;67(3):927-31 Epub 1996/09/01.

30. Cao H, Garcia F, McNiven MA. Differential distribution of dynamin isoforms in mammalian cells. Mol Biol Cell. 1998;9(9):2595-609 Epub 1998/09/03.

31. Raimondi A, Ferguson SM, Lou X, Armbruster M, Paradise S, Giovedi S, et al. Overlapping role of dynamin isoforms in synaptic vesicle endocytosis. Neuron. 2011:70(6):1100-14 Epub 2011/06/22.

32. Singh $M$, Jadhav $H R$, Bhatt $T$. Dynamin functions and ligands: classical mechanisms behind. Mol Pharmacol. 2017;91(2):123-34 Epub 2016/11/24

33. Ferguson SM, Raimondi A, Paradise S, Shen H, Mesaki K, Ferguson A, et al. Coordinated actions of actin and BAR proteins upstream of dynamin at endocytic clathrin-coated pits. Dev Cell. 2009;17(6):811-22 Epub 2010/01/12.

34. Mayor S, Parton RG, Donaldson JG. Clathrin-independent pathways of endocytosis. Cold Spring Harb Perspect Biol. 2014;6(6):a016758 Epub 2014/06/04.

35. Parton RG, Collins BM. Unraveling the architecture of caveolae. Proc Natl Acad Sci U S A. 2016;113(50):14170-2 Epub 2016/12/03.

36. Banach-Orlowska M, Wyszynska R, Pyrzynska B, Maksymowicz M, Golab J, Miaczynska M. Cholesterol restricts lymphotoxin beta receptor-triggered NFkappaB signaling. Cell Commun Signal. 2019;17(1):171 Epub 2019/12/28.

37. Lamaze C, Dujeancourt A, Baba T, Lo CG, Benmerah A, Dautry-Varsat A. Interleukin 2 receptors and detergent-resistant membrane domains define a clathrin-independent endocytic pathway. Mol Cell. 2001;7(3):661-71 Epub 2001/07/21

38. Jastrzebski K, Zdzalik-Bielecka D, Maminska A, Kalaidzidis Y, Hellberg C, Miaczynska M. Multiple routes of endocytic internalization of PDGFRbeta contribute to PDGF-induced STAT3 signaling. J Cell Sci. 2017;130(3):577-89 Epub 2016/12/17

39. Riento K, Ridley AJ. Rocks: multifunctional kinases in cell behaviour. Nat Rev Mol Cell Biol. 2003;4(6):446-56 Epub 2003/06/05.

40. Sabharanjak S, Sharma P, Parton RG, Mayor S. GPI-anchored proteins are delivered to recycling endosomes via a distinct cdc42-regulated, clathrin- 
independent pinocytic pathway. Dev Cell. 2002;2(4):411-23 Epub 2002/04/ 24.

41. Kirkham M, Fujita A, Chadda R, Nixon SJ, Kurzchalia TV, Sharma DK, et al. Ultrastructural identification of uncoated caveolin-independent early endocytic vehicles. J Cell Biol. 2005;168(3):465-76 Epub 2005/01/26.

42. Lundmark R, Doherty GJ, Howes MT, Cortese K, Vallis Y, Parton RG, et al. The GTPase-activating protein GRAF1 regulates the CLIC/GEEC endocytic pathway. Curr Biol. 2008;18(22):1802-8 Epub 2008/11/28.

43. Glebov OO, Bright NA, Nichols BJ. Flotillin-1 defines a clathrin-independent endocytic pathway in mammalian cells. Nat Cell Biol. 2006;8(1):46-54 Epub 2005/12/13.

44. Meister $\mathrm{M}$, Tikkanen $\mathrm{R}$. Endocytic trafficking of membrane-bound cargo: a flotillin point of view. Membranes. 2014;4(3):356-71 Epub 2014/07/16.

45. Naslavsky N, Weigert R, Donaldson JG. Characterization of a nonclathrin endocytic pathway: membrane cargo and lipid requirements. Mol Biol Cell. 2004;15(8):3542-52 Epub 2004/05/18.

46. Sandvig K, Kavaliauskiene S, Skotland T. Clathrin-independent endocytosis: an increasing degree of complexity. Histochem Cell Biol. 2018;150(2):107-18 Epub 2018/05/19.

47. Boucrot E, Ferreira AP, Almeida-Souza L, Debard S, Vallis Y, Howard G, et al. Endophilin marks and controls a clathrin-independent endocytic pathway. Nature. 2015;517(7535):460-5 Epub 2014/12/18.

48. Sorkin A, von Zastrow M. Endocytosis and signalling: intertwining molecular networks. Nat Rev Mol Cell Biol. 2009;10(9):609-22 Epub 2009/08/22.

49. Miaczynska M. Effects of membrane trafficking on signaling by receptor tyrosine kinases. Cold Spring Harb Perspect Biol. 2013;5(11):a009035 Epub 2013/11/05.

50. Irannejad R, Tsvetanova NG, Lobingier BT, von Zastrow M. Effects of endocytosis on receptor-mediated signaling. Curr Opin Cell Biol. 2015;35: 137-43 Epub 2015/06/10

51. Barbieri E, Di Fiore PP, Sigismund S. Endocytic control of signaling at the plasma membrane. Curr Opin Cell Biol. 2016;39:21-7 Epub 2016/02/13.

52. Penheiter SG, Mitchell H, Garamszegi N, Edens M, Dore JJ Jr, Leof EB. Internalization-dependent and -independent requirements for transforming growth factor beta receptor signaling via the Smad pathway. Mol Cell Biol. 2002;22(13):4750-9 Epub 2002/06/08.

53. Budick-Harmelin N, Miaczynska M. Integration of the Endocytic system into the network of cellular functions. Prog Mol Subcell Biol. 2018;57:39-63 Epub 2018/08/12.

54. Lobingier BT, von Zastrow M. When trafficking and signaling mix: how subcellular location shapes $\mathrm{G}$ protein-coupled receptor activation of heterotrimeric G proteins. Traffic. 2019;20(2):130-6 Epub 2018/12/24.

55. Weinberg ZY, Puthenveedu MA. Regulation of $G$ protein-coupled receptor signaling by plasma membrane organization and endocytosis. Traffic. 2019; 20(2):121-9 Epub 2018/12/12

56. Lu TT, Browning JL. Role of the Lymphotoxin/LIGHT system in the development and maintenance of reticular networks and vasculature in lymphoid tissues. Front Immunol. 2014;5:47 Epub 2014/02/28.

57. Buettner $\mathrm{M}$, Lochner $\mathrm{M}$. Development and function of secondary and tertiary lymphoid organs in the small intestine and the colon. Front Immunol. 2016;7:342 Epub 2016/09/23.

58. Seleznik GM, Zoller J, O'Connor T, Graf R, Heikenwalder M. The role of lymphotoxin signaling in the development of autoimmune pancreatitis and associated secondary extra-pancreatic pathologies. Cytokine Growth Factor Rev. 2014;25(2):125-37 Epub 2014/02/11.

59. Maminska A, Bartosik A, Banach-Orlowska M, Pilecka I, Jastrzebski K, ZdzalikBielecka D, et al. ESCRT proteins restrict constitutive NF-kappaB signaling by trafficking cytokine receptors. Sci Signal. 2016;9(411):ra8 Epub 2016/01/21.

60. Banach-Orlowska M, Jastrzebski K, Cendrowski J, Maksymowicz M, Wojciechowska K, Korostynski M, et al. The topology of the lymphotoxin beta receptor that accumulates upon endolysosomal dysfunction dictates the NFkappaB signaling outcome. J Cell Sci. 2018;131(22):jcs218883 Epub 2018/10/20.

61. Ganeff C, Remouchamps C, Boutaffala L, Benezech C, Galopin G, Vandepaer $S$, et al. Induction of the alternative NF-kappaB pathway by lymphotoxin alphabeta (LTalphabeta) relies on internalization of LTbeta receptor. Mol Cell Biol. 2011;31(21):4319-34 Epub 2011/09/08.

62. Sadowski L, Jastrzebski K, Kalaidzidis Y, Heldin CH, Hellberg C, Miaczynska M. Dynamin inhibitors impair endocytosis and mitogenic signaling of PDGF. Traffic. 2013;14(6):725-36 Epub 2013/02/22.

63. Rink J, Ghigo E, Kalaidzidis Y, Zerial M. Rab conversion as a mechanism of progression from early to late endosomes. Cell. 2005;122(5):735-49 Epub 2005/09/07.
64. Collinet C, Stoter M, Bradshaw CR, Samusik N, Rink JC, Kenski D, et al. Systems survey of endocytosis by multiparametric image analysis. Nature. 2010;464(7286):243-9 Epub 2010/03/02

65. Kalaidzidis Y, Kalaidzidis I, Zerial M. A probabilistic method to quantify the colocalization of markers on intracellular vesicular structures visualized by light microscopy. AIP Conference Proc. 2015;1641 (1):580-7.

66. Schneider CA, Rasband WS, Eliceiri KW. NIH image to ImageJ: 25 years of image analysis. Nat Methods. 2012;9(7):671-5 Epub 2012/08/30.

67. Doench JG, Fusi N, Sullender M, Hegde M, Vaimberg EW, Donovan KF, et al. Optimized sgRNA design to maximize activity and minimize off-target effects of CRISPR-Cas9. Nat Biotechnol. 2016;34(2):184-91 Epub 2016/01/19.

68. Joung J, Konermann S, Gootenberg JS, Abudayyeh OO, Platt RJ, Brigham $M D$, et al. Genome-scale CRISPR-Cas9 knockout and transcriptional activation screening. Nat Protoc. 2017;12(4):828-63 Epub 2017/03/24.

69. van Dam EM, Stoorvogel W. Dynamin-dependent transferrin receptor recycling by endosome-derived clathrin-coated vesicles. Mol Biol Cell. 2002; 13(1):169-82 Epub 2002/01/26

70. van Dam EM, Ten Broeke T, Jansen K, Spijkers P, Stoorvogel W. Endocytosed transferrin receptors recycle via distinct dynamin and phosphatidylinositol 3-kinasedependent pathways. J Biol Chem. 2002;277(50):48876-83 Epub 2002/10/10.

71. Wang LH, Rothberg KG, Anderson RG. Mis-assembly of clathrin lattices on endosomes reveals a regulatory switch for coated pit formation. J Cell Biol. 1993;123(5):1107-17 Epub 1993/12/01.

72. Macia E, Ehrlich M, Massol R, Boucrot E, Brunner C, Kirchhausen T. Dynasore, a cellpermeable inhibitor of dynamin. Dev Cell. 2006;10(6):839-50 Epub 2006/06/03.

73. Kelly BT, McCoy AJ, Spate K, Miller SE, Evans PR, Honing S, et al. A structural explanation for the binding of endocytic dileucine motifs by the AP2 complex. Nature. 2008;456(7224):976-9 Epub 2009/01/14.

74. Surviladze Z, Waller A, Strouse JJ, Bologa C, Ursu O, Salas V, et al. A potent and selective inhibitor of Cdc42 GTPase. Bethesda: Probe Reports from the $\mathrm{NIH}$ Molecular Libraries Program; 2010.

75. Hong L, Kenney SR, Phillips GK, Simpson D, Schroeder CE, Noth J, et al. Characterization of a Cdc42 protein inhibitor and its use as a molecular probe. J Biol Chem. 2013;288(12):8531-43 Epub 2013/02/06.

76. Watson JR, Owen D, Mott HR. Cdc42 in actin dynamics: an ordered pathway governed by complex equilibria and directional effector handover. Small GTPases. 2017;8(4):237-44 Epub 2016/10/08.

77. Haskill S, Beg AA, Tompkins SM, Morris JS, Yurochko AD, Sampson-Johannes A, et al. Characterization of an immediate-early gene induced in adherent monocytes that encodes I kappa B-like activity. Cell. 1991;65(7):1281-9 Epub 1991/07/08.

78. Escobar GA, McIntyre RC Jr, Moore EE, Gamboni-Robertson F, Banerjee A. Clathrin heavy chain is required for TNF-induced inflammatory signaling. Surgery. 2006;140(2):268-72 Epub 2006/08/15

79. Hunter I, Nixon GF. Spatial compartmentalization of tumor necrosis factor (TNF) receptor 1-dependent signaling pathways in human airway smooth muscle cells. Lipid rafts are essential for TNF-alpha-mediated activation of RhoA but dispensable for the activation of the NF-kappaB and MAPK pathways. J Biol Chem. 2006;281(45):34705-15 Epub 2006/09/20.

80. D'Alessio A, Al-Lamki RS, Bradley JR, Pober JS. Caveolae participate in tumor necrosis factor receptor 1 signaling and internalization in a human endothelial cell line. Am J Pathol. 2005;166(4):1273-82 Epub 2005/03/29.

81. Pust S, Klokk TI, Musa N, Jenstad M, Risberg B, Erikstein B, et al. Flotillins as regulators of ErbB2 levels in breast cancer. Oncogene. 2013;32(29):3443-51 Epub 2012/08/08.

82. Buser DP, Ritz MF, Moes S, Tostado C, Frank S, Spiess M, et al. Quantitative proteomics reveals reduction of endocytic machinery components in gliomas. EBioMedicine. 2019;46:32-41 Epub 2019/07/25.

83. Chen L, Deng H, Cui H, Fang J, Zuo Z, Deng J, et al. Inflammatory responses and inflammation-associated diseases in organs. Oncotarget. 2018;9(6): 7204-18 Epub 2018/02/23.

84. Force WR, Glass AA, Benedict CA, Cheung TC, Lama J, Ware CF. Discrete signaling regions in the lymphotoxin-beta receptor for tumor necrosis factor receptor-associated factor binding, subcellular localization, and activation of cell death and NF-kappaB pathways. J Biol Chem. 2000;275(15): 11121-9 Epub 2001/02/07

85. Szymanska E, Skowronek A, Miaczynska M. Impaired dynamin 2 function leads to increased AP-1 transcriptional activity through the JNK/c-Jun pathway. Cell Signal. 2016;28(1):160-71 Epub 2015/10/18.

86. Kim ML, Sorg I, Arrieumerlou C. Endocytosis-independent function of clathrin heavy chain in the control of basal NF-kappaB activation. PLoS One. 2011;6(2):e17158 Epub 2011/03/03. 
87. Fujioka S, Niu J, Schmidt C, Sclabas GM, Peng B, Uwagawa T, et al. NF-kappaB and AP-1 connection: mechanism of NF-kappaB-dependent regulation of AP-1 activity. Mol Cell Biol. 2004;24(17):7806-19 Epub 2004/08/18.

88. Sousa LP, Lax I, Shen H, Ferguson SM, De Camilli P, Schlessinger t.

Suppression of EGFR endocytosis by dynamin depletion reveals that EGFR signaling occurs primarily at the plasma membrane. Proc Natl Acad Sci U S A. 2012;109(12):4419-24 Epub 2012/03/01.

89. Bagaev AV, Garaeva AY, Lebedeva ES, Pichugin AV, Ataullakhanov RI, Ataullakhanov Fl. Elevated pre-activation basal level of nuclear NF-kappaB in native macrophages accelerates LPS-induced translocation of cytosolic NFkappaB into the cell nucleus. Sci Rep. 2019;9(1):4563 Epub 2019/03/16.

\section{Publisher's Note}

Springer Nature remains neutral with regard to jurisdictional claims in published maps and institutional affiliations.

Ready to submit your research? Choose BMC and benefit from:

- fast, convenient online submission

- thorough peer review by experienced researchers in your field

- rapid publication on acceptance

- support for research data, including large and complex data types

- gold Open Access which fosters wider collaboration and increased citations

- maximum visibility for your research: over $100 \mathrm{M}$ website views per year

At BMC, research is always in progress.

Learn more biomedcentral.com/submissions 